\title{
CRISPR therapeutic tools for complex genetic disorders and cancer (Review)
}

\author{
STELLA BALIOU $^{1}$, MARIA ADAMAKI ${ }^{1}$, ANTHONY M. KYRIAKOPOULOS ${ }^{2}$, DEMETRIOS A. SPANDIDOS ${ }^{3}$ \\ MIHALIS PANAYIOTIDIS ${ }^{4}$, IOANNIS CHRISTODOULOU ${ }^{1}$ and VASSILIS ZOUMPOURLIS ${ }^{1}$ \\ ${ }^{1}$ National Hellenic Research Foundation, 11635 Athens; ${ }^{2}$ Nasco AD Biotechnology Laboratory, 18536 Piraeus; \\ ${ }^{3}$ Laboratory of Clinical Virology, Medical School, University of Crete, Heraklion 71003, Greece; \\ ${ }^{4}$ Department of Applied Sciences, Northumbria University, Newcastle Upon Tyne, NE1 8ST, UK
}

Received March 2, 2018; Accepted May 18, 2018

DOI: $10.3892 /$ ijo.2018.4434

\begin{abstract}
One of the fundamental discoveries in the field of biology is the ability to modulate the genome and to monitor the functional outputs derived from genomic alterations. In order to unravel new therapeutic options, scientists had initially focused on inducing genetic alterations in primary cells, in established cancer cell lines and mouse models using either RNA interference or cDNA overexpression or various programmable nucleases [zinc finger nucleases (ZNF), transcription activator-like effector nucleases (TALEN)]. Even though a huge volume of data was produced, its use was neither cheap nor accurate. Therefore, the clustered regularly interspaced short palindromic repeats (CRISPR) system was
\end{abstract}

Correspondence to: Dr Vassilis Zoumpourlis, National Hellenic Research Foundation, 48 Vas. Konstantinou Avenue, 11635 Athens, Greece

E-mail:vzub@eie.gr

Abbreviations: ABC, activated B cell-like type; AML, acute myeloid leukemia; Apc, adenomatous polyposis coli; ART, antiretroviral therapy; APOBEC1, apolipoprotein B mRNA editing enzyme catalytic polypeptide-like family protein 1; aSyn, A-synuclein; HXTCs, broadlyspecific cytotoxic T cells; CCLE, Cancer Cell Line Encyclopedia; CGA, Cancer Genome Atlas; Ctnnb1, cateninb1 gene; CPP, cell penetrating peptide; CFTR, CF transmembrane conductor receptor; CARs, chimeric antigen receptors; CGD, chronic granulomatous disease; CRISPR, clustered regularly interspaced short palindromic repeats; CTOL, colorectal tumor organoid library; CRISPRa screens, CRISPR activation screens; Cas9, CRISPR-associated protein 9; CRISPRi, CRISPR interference; CRISPRn screens, CRISPR nuclease screens; crRNA, CRISPR RNA; CMV, cytomegalovirus; dCas9, deactivated version of Cas9 nuclease; $D O C K 8$, dedicator of cytokinesis 8 ; DLBCL, Diffuse large B cell lymphoma; Digenome-seq, digested genome sequencing; DSBs, double-strand breaks; Eml4-Alk fusion protein, echinoderm microtubule associated protein like 4-anaplastic lymphoma kinase; ENCODE, Encyclopedia of DNA Elements; EGFR, epidermal growth factor receptor; EBV, Epstein-Barr virus; Ecm, extracellular matrix; Flt3-ITD, Flt3 internal tandem duplication; GEMMs, genetically engineered mouse models; GWAS, genome-wide association studies; HSPCs, hematopoietic stem and progenitor cells; HBV, hepatitis B virus; HDR, homology directed repair; HBB, human hemoglobin beta gene; HITI, homology-independent targeted integration; evidenced to be the next step in genome engineering tools. CRISPR-associated protein 9 (Cas9)-mediated genetic perturbation is simple, precise and highly efficient, empowering researchers to apply this method to immortalized cancerous cell lines, primary cells derived from mouse and human origins, xenografts, induced pluripotent stem cells, organoid cultures, as well as the generation of genetically engineered animal models. In this review, we assess the development of the CRISPR system and its therapeutic applications to a wide range of complex diseases (particularly distinct tumors), aiming at personalized therapy. Special emphasis is given to organoids and CRISPR screens in the design of innovative therapeutic

HIV, human immunodeficiency virus; ICF, immunodeficiency centromeric region instability facial anomalies syndrome; iPSCs, induced pluripotent stem cells; IDLV, integrase-defective lentiviral vector; LAM-PCR, linear amplification-mediated PCR; LNPs, lipid nanoparticles; LTR, long terminal repeats; HTGTS, highthroughput genome-wide translocation sequencing; HD, Huntington's disease; $H B B$, hemoglobin subunit beta; HTT, Huntingtin gene; GUIDE-seq, genome-wide unbiased identification of DSBs enabled by sequencing; LCA10, Leber congenital amaurosis 10; MAPK, mitogen-activated protein kinase; Mll3, mixed lineage leukemia 3; MGEs, mobile genetic elements; MOI, multiplicity of infection; NHEJ, non-homologous end joining; NSCLC, non-small cell lung cancer; PI3K, phosphoinositide 3-kinase; Pten, phosphatase and tensin homolog; PanINs, pre-invasive pancreatic intraepithelial neoplasms; PAM, protospacer adjacent motif; RFLP, restriction fragment length polymorphism; RNPs, ribonucleoproteins; RFN, RNA-guided FokI-dCas9 nuclease; RNA-seq, RNA sequencing; RCT, rolling circle transcription; SCD, sickle cell disease; sgRNA, single-guide RNA; SNPs, single nucleotide polymorphisms; ssRNA, single-strand RNA;SSCs, spermatogonial stem cells; TCRs, T cell receptors; TRAC, $\mathrm{T}$ cell receptor alpha constant; 3D, three-dimensional; tracrRNA, trans-activating RNA;TALEN, transcription activator-like effector nuclease; TGF, transforming growth factor; TSS, transcriptional start site; TKIs, tyrosine kinase inhibitors; UGI, unique guide index; vQS, viral quasispecies; ZNFs, Zinc finger nucleases

Key words: CRISPR, therapeutics, personalized therapy, complex genetic disorders, cancer 
approaches. Overall, the CRISPR system is regarded as an eminent genome engineering tool in therapeutics. We envision a new era in cancer biology during which the CRISPR-based genome engineering toolbox will serve as the fundamental conduit between the bench and the bedside; nonetheless, certain obstacles need to be addressed, such as the eradication of side-effects, maximization of efficiency, the assurance of delivery and the elimination of immunogenicity.

\section{Contents}

1. The principle of the CRISPR genome engineering tool

2 . The revolution in generating animal models and cell lines

3. Germ-line gene editing through the CRISPR system

4. CRISPR system: A therapeutic tool in a wide range of genetic diseases

5. Organoids: Smart weapons against complex genetic diseases

6. Applying bioengineering approaches and creating the appropriate niche to improve organoid-based therapies 'in vivo'

7. Towards personalized therapy

8. The contribution of functional genome-wide pooled sgRNA screens

9. The combination of immune and CRISPR system against complex diseases

10. The CRISPR system against HIV infection

11. Challenges associated with the CRISPR-based gene method and alternative methods

12. Ways to circumvent the off-target effects of the CRISPR system

13. Conclusions

\section{The principle of the CRISPR genome engineering tool}

Over the past decades, genome editing technologies have been composed of zinc-finger nucleases (ZFNs) and transcriptional activator-like effector nucleases (TALENs), empowering scientific results at both the basic and clinical level $(1,2)$. Despite the advances that have been reported in the field of genomic engineering, the use of ZNF or TALEN nucleases is associated with several obstacles. For example, the design for genomic engineering techniques remains complex, and therefore, these techniques cannot modulate the expression of multiple target genes. The principle in using ZNFs and TALENs is protein-based and the associated toxicity is very high (3) (Table I), thus prompting researchers to uncover a novel genome engineering tool.

A novel RNA-guided endonuclease-relied genome editing technology that was termed the clustered regularly interspaced short palindromic repeats (CRISPR)-associated protein 9 (Cas9) system, markedly altered the landscape of genomic engineering $(4,5)$. The story began with the study of the immune system in bacteria and archaea in an attempt to elucidate the mechanisms through which these organisms combat viral infection. In native context, it was found that CRISPR in combination with Cas protein provide bacteria with immunity against infections. Specifically, it was shown that the role of repeats was to recognize mobile genetic elements (MGEs), and thus it was possible to cut them into small sequences and integrate them as spacers into the genome of bacteria. That approach was based on the microbial immune system that used RNA-guided nuclease to recognize and cleave foreign genetic elements (6,7). In 2012, an adaptation of the prokaryotic immune system in mammalian cells as a gene editing tool was simultaneously reported for the first time by four different research groups [Mali et al (8), Wright et al (9), Jinek et al (14), Swiech et al (30)], causing a certain debate regarding the intellectual rights of this innovative technique. The newly engineered CRISPR system consisted of two components: A chimeric single-guide RNA (sgRNA) that provided target specificity and Cas 9 that acted as a helicase and a nuclease in order to unwind and cut the target DNA $(4,8)$. In this system, the only restriction for the targeting of a specific locus was the protospacer adjacent motif (PAM) sequence ('NGG' in the case of SpCas9) (6).

The CRISPR system was further simplified, based on its ability to interfere with and participate in bacterial adaptive immunity, comprising Cas nuclease and single-guide RNA (sgRNA). In general, the CRISPR system main mechanism of action is mediated by the Cas nuclease, which interacts with DNA and generates double-strand breaks (DSBs) in the DNA sequence, and also matches the broken genomic region with a sgRNA. The sgRNA is a chimeric RNA, which consists of programmable CRISPR RNA (crRNA) and a transactivating RNA (tracrRNA) (9). Specifically, the CRISPR-Cas system includes a cluster of proteins, categorized into Class 1 (Types I, III and IV) and Class 2 (Types II, V, VI) (7), all of which constitute specific RNA-guided DNA endonuclease proteins (Cas) (7,9-11). Cas proteins are driven by RNA and not by other proteins, to recognize the desired DNA sequence. The Class 2 subtype of the CRISPR system, which generally exploits Cas9 nuclease, is usually selected (9-11). The $100 \mathrm{bp}$ sgRNA forms complementary bonds with the target DNA sequence of 17-20 nucleotides, via Watson-Crick base pairing, and the tracrRNA is the component which Cas9 nuclease binds to. Specifically, the sgRNA recognizes the target sequence, which is located upstream of the triplicate sequence named PAM, given that the PAM motif recruits Cas9 nuclease at site of DNA cleavage (12) (Fig. 1). Of note, the PAM sequence plays the determinant role in recognizing the correct DNA sequence and in preventing the direction of RNA to self-targets and non-specific sequences (13). This is possible as repeats of the CRISPR system do not involve PAM and the orientation of Cas9 depends on the PAM sequence (14). Overall, the genomic sequence of 14 nucleotides defines the target at which Cas9 nuclease exerts its effects (15). More specifically, this sequence is composed of 12 nucleotides of sgRNA in conjunction with two nucleotides of protospacer adjacent motif. Notably, there is a wide range of PAM sequences depending on their origin (16). In the case of Cas9 derived from Streptococcus pyogenes, the motif of the PAM sequence may be composed of any base, followed by two additional guanine bases (16).

The CRISPR system is sufficient on its own to instigate double helical DNA breaks, which can be repaired by nonhomologous end joining (NHEJ) or homology directed repair (HDR). However, the efficiency and specificity of the CRISPR system are not based on DNA repair mecha- 
Table I. Comparison of genome engineering tools properties.

\begin{tabular}{llll}
\hline Properties & \multicolumn{1}{c}{ ZNF } & TALEN & CRISPR \\
\hline DNA-binding moiety & Protein & Protein & RNA \\
Target recognition size & $18-36$ nucleotides & $30-40$ nucleotides & 22 nucleotides \\
Nuclease & FokI & FokI & Cas \\
Toxicity & Variable to high & Low & Low \\
Complexity of design & Very complex & Complex & Simple \\
Ease of targeting multiple targets & Low & Low & High \\
Off-target effects & Moderate & Low & Variable \\
\hline
\end{tabular}

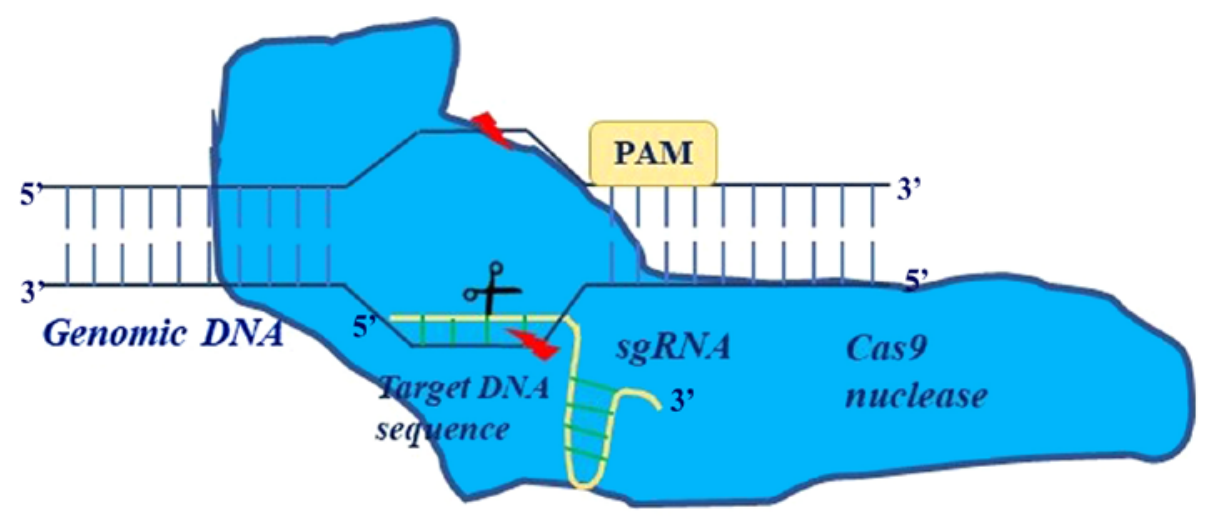

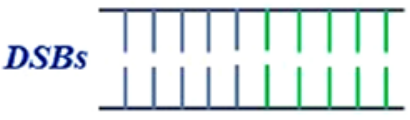

NHEJ

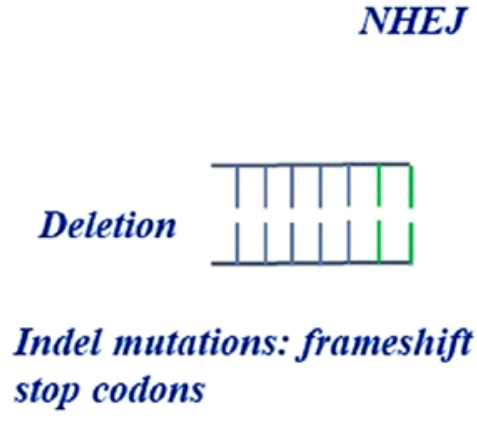

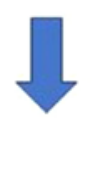

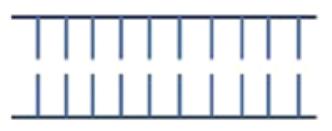

$H D R$

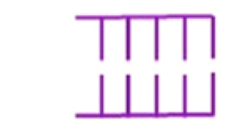

Donor

template

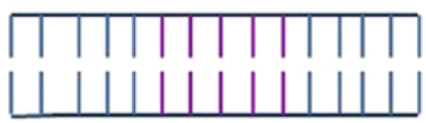

Figure 1. CRISPR system mechanism of action. The main action of the CRISPR system is mediated by the Cas nuclease. This nuclease is recruited to DNA by the orientation of the PAM motif and generates double-strand breaks in DNA sequence, matching the broken genomic region with a single guide RNA. Following this, non-homologous end joining or homologous mediated repair mechanisms are conducted to restore the nucleotide sequence induced by doublestrand breaks, causing the anticipated genomic alterations. CRISPR, clustered regularly interspaced short palindromic repeats; PAM, protospacer adjacent motif; DSBs, double-strand breaks; NHEJ, non-homologous end joining; HDR, homology directed repair.

nisms (17). In the NHEJ repair mechanism, the DNA ends are chemically ligated back together with a small insertion or deletion at the site of the break. Thus, the NHEJ mechanism is usually employed in cases of gene disruption (small deletions or insertions), inversions, duplications or deletions, whereas the HDR repair mechanism is used for large deletions, base mutations, insertions and replacements (Fig. 2). In the HDR repair mechanism, a donor DNA molecule matches with the genomic sequence flanking the site of the DSB, thus introducing new genetic information into the genome at the site of the break. The CRISPR technique can utilize the HDR mechanism by using single-strand DNA oligonucleotides in order to cause silent mutations, thus allowing us to monitor the anticipated phenotype in a particular cell type $(18,19)$. Notably, the repair pathway is selected based on the phases of the cell cycle; the NHEJ mechanism is employed in cells that are at the G1, S and 


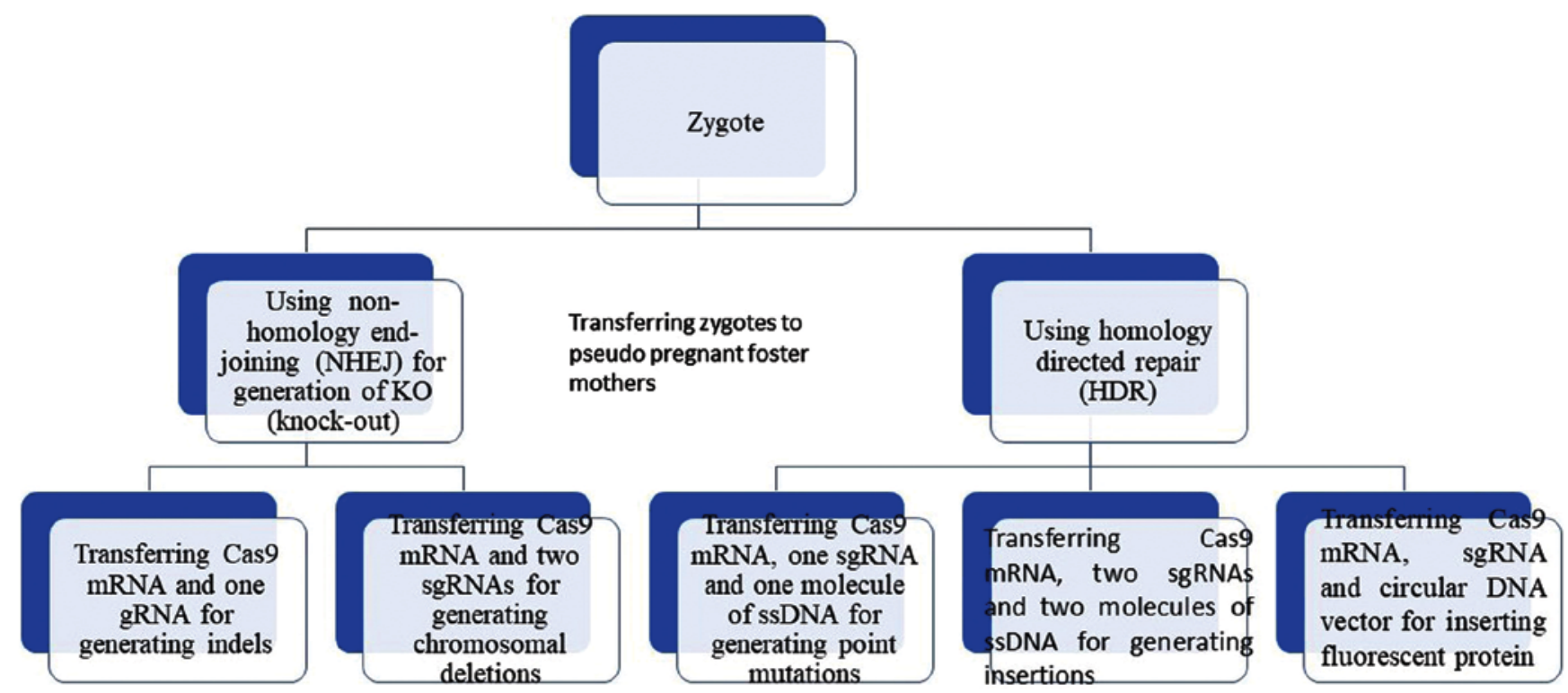

Figure 2. The use of two distinct repair pathways in performing different modifications. In the NHEJ mechanism, the ends of the DNA are chemically ligated back together with a small insertion or deletion at the site of the break. The NHEJ mechanism is usually employed in cases of gene disruption (small deletions or insertions), inversions, duplications or deletions whereas the HDR mechanism is used for deletions, base mutations, insertions and replacements. In HDR, a donor DNA molecule matches with the genomic sequence flanking the site of the double-strand break and thus it can be integrated into the genome at the site of the break, introducing new genetic information into the genome. NHEJ, non-homologous end joining; HDR, homology directed repair; sgRNA, single-chimeric guide RNA.

G2 phases, whereas the HDR mechanism is restricted to the $\mathrm{S}$ and $\mathrm{G} 2$ phases (20).

Nonetheless, the major challenge when using both DNA-repair mechanisms is the creation of DSBs, which can either trigger signaling cascades mediated by DNA damage checkpoints or cause the formation of gene translocations $(21,22)$. In the case of the NHEJ repair mechanism, most obstacles are related to disrupting the open reading frames of genes, considering that the ligation of two ends after DSBs is error-prone. The HDR repair mechanism, on the other hand, is characterized by low efficiency, particularly in non-dividing cells, despite its high overall accuracy as a repair mechanism. Therefore, the CRISPR method has been modified as an alternative to the above repair mechanisms, using cytidine deaminases fused to Cas9 nickase, aiming to circumvent the formation of DSBs and to implement the process in non-diving cells. Specifically, it has been shown that the association of Cas9-D10A nickases mutant with apolipoprotein B mRNA editing enzyme catalytic polypeptide-like family protein 1 (APOBEC1) and uracil glycosylase inhibitor (UGI), leads to a $37 \%$ increase in CRISPR efficiency (23).

The homology-independent targeted integration (HITI) constitutes another advancement of the CRISPR system, as it surpasses the limitations met in both repair mechanisms (NHEJ and HDR). HITI takes advantage of the NHEJ mechanism and aims at specific gene modifications (24). Characteristically, it has been documented that the most effective HITI rate is at $55.9 \%$ in neurons, as compared to HDR (1-3\% efficiency) (24). These examples constitute irrefutable evidence of the advancements that have been made in order to accommodate the 'in vivo' delivery of the CRISPR system, including non-dividing cells.

The structural elements of the CRISPR system through which Cas9 is assembled to RNA and DNA sequence include a
T-shaped configuration comprising the four stem cell loops, the linker region and the repeat: anti-repeat binary complex (25). The formation of stem cell loops has been reported to be crucial for the efficiency and stability of the CRISPR-sgRNA complex (25).

In the field of functional studies, the CRISPR system has rapidly revolutionized genetic engineering, allowing researchers to easily alter a vast range of genomes. The mechanism of the pioneer CRISPR approach is based on RNA-DNA interaction, whereas previous genome editing tools (ZNFs and TALENs) were based on protein-DNA associations $(2,26)$ (Table I). The properties of the CRISPR system that render it amenable are as follows: its simplicity in constructing the Cas9 nuclease and its capacity to target many genomic loci simultaneously. Notably, the CRISPR system has been distinguished over other approaches, as it enables the simultaneous study of numerous genetic modifications in one step, based on the method of multiplex target recognition, which uses many sgRNAs at the cellular level (27). The multiplex capacity of the CRISPR system is invaluable in studying the underlying molecular mechanisms that are implicated in tumor progression, given that cancer is a multistep procedure that involves the accumulation of genetic changes, such as mutations, genome rearrangements and epigenetic alterations $(28,29)$. Furthermore, the potential redundancy among several genes in a functional output can be delineated using the CRISPR method. For example, it has been shown that the Cas9-mediated elimination of each DNA methyltransferase in mouse brains highlights the role of any DNA methyltransferase in the memory compartment (30). The CRISPR system has proven to be efficient in inducing a wide variety of genetic modifications, ranging from the elimination and mutations of genes to genomic insertions $(4,8,31,32)$, inversions $(33,34)$ and translocations $(21,32,35,36)$. For example, the insertion of one 
Table II. Cancer therapeutics arising from the CRISPR system.

\begin{tabular}{|c|c|c|c|c|}
\hline Cancer type & Modification & Contribution to therapy & Authors/(Refs.), year & Journal \\
\hline Breast cancer & $\begin{array}{l}\text { Knock-out of } \\
\text { miR-644a }\end{array}$ & $\begin{array}{l}\text { Inhibition of tumor growth, } \\
\text { metastasis, and drug resistance }\end{array}$ & Raza et al (227), 2016 & Oncotarget \\
\hline Breast cancer & $\begin{array}{l}\text { Knock-out (KO) } \\
\text { BC200 lncRNA by } \\
\text { CRISPR system }\end{array}$ & $\begin{array}{l}\text { BC200 may serve as a prognostic } \\
\text { marker and possible target } \\
\text { for attenuating deregulated } \\
\text { cell proliferation } \\
\text { in estrogen-dependent breast cancer }\end{array}$ & Singh et al (228), 2016 & $\begin{array}{l}\text { Cell Death } \\
\text { and Disease }\end{array}$ \\
\hline $\begin{array}{l}\text { Endometrial } \\
\text { cancer }\end{array}$ & $\begin{array}{l}\text { Knock-out of } \\
M U C 1 \text { at cells } \\
\text { by CRISPR system }\end{array}$ & $\begin{array}{l}\text { Concomitant decrease of MUC1 and } \\
\text { EGFR can be prognostic markers } \\
\text { in human endometrial tumors }\end{array}$ & Engel et al (229), 2016 & Oncotarget \\
\hline $\begin{array}{l}\text { Lung } \\
\text { adenocarcinoma } \\
\text { and endometrial } \\
\text { carcinoma }\end{array}$ & $\begin{array}{l}\text { Deletion of super- } \\
\text { enhancers } 3^{\prime} \text { to } M Y C \\
\text { in cells by using } \\
\text { CRISPR system }\end{array}$ & $\begin{array}{l}\text { Super-enhancers } \\
\text { stimulate cancer driver genes } \\
\text { in diverse types of cancer }\end{array}$ & Zhang et al (230), 2016 & Nature Genetics \\
\hline $\begin{array}{l}\text { Endometrial } \\
\text { cancer }\end{array}$ & $\begin{array}{l}E R \alpha \text {-null } \\
\text { endometrial } \\
\text { cancer cells }\end{array}$ & $\begin{array}{l}\text { Inverse relationship between the tumor } \\
\text { suppressor PR and the oncogene } \\
\text { Myc in endometrial cancer }\end{array}$ & Kavlashvili et al (231), 2016 & PLOS One \\
\hline $\begin{array}{l}\text { Prostate } \\
\text { cancer }\end{array}$ & $\begin{array}{l}\text { NANOG and } \\
\text { NANOGP } 8 \text { knockout } \\
\text { DU145 prostate } \\
\text { cancer cell lines }\end{array}$ & $\begin{array}{l}\text { Attenuation of malignant potential } \\
\text { of prostate cancer }\end{array}$ & Kawamura et al (232), 2015 & Oncotarget \\
\hline
\end{tabular}

specific DNA template can be accomplished using HDR with duplex DNA templates $(4,8,31,32)$ or single-strand oligonucleotides $(31,37-41)$ or viral encoded templates $(42,43)$. In addition, the Cas 9 nuclease appears to be superior to other nucleases, as it has the ability not only to induce gain-of-function and lossof-function mutations, but also to cause specific modifications.

To sum up, the CRISPR technology comes with a surge of excitement, as it can be applied to a wide range of biological models, including immortalized cancerous lines, primary cells derived from mouse and human origins, xenografts, organoid cultures, as well as the generation of genetically engineered animal models. The CRISPR technology can be employed for the comprehensive dissection of oncogenic signaling pathways via sequential or multiplex gene editing. We envision a new era in cancer biology during which CRISPR-based genome engineering will serve as an important link between the bench and the bedside. The successful implementation of sophisticated genetic technology aims at the comprehensive characterization of tumors individually in patients, thus paving the road for the development of tailored cell-based or whole animal-based experimental systems.

\section{The revolution in generating animal models and cell lines}

Cell and animal models play an essential role in expanding our knowledge in the field of tumor biology. Undoubtedly, the use of classical biological systems is crucial for evaluating the efficacy of various potential therapeutic drugs. In this review, we analyze the mechanisms of action of the CRISPR system, compare it with other gene editing tools and discuss its contribution to the generation of genetically engineered mouse models (GEMMs), cell lines or organoids. The table below summarizes the advances achieved to date with Cas9 nuclease in introducing genetic changes that appear to have therapeutic potential in several cancer subtypes (Table II). The CRISPR system has been implemented not only in classical biological models, but also in primary cells, such as induced pluripotent stem cells (iPSCs), with the aim to identify novel oncogenic pathways and consequently novel therapeutic options against diverse cancer subtypes.

Genetically-engineered mouse models have been extensively used in the study of tumorigenesis mechanisms and in the design of drugs that confer tumor resistance $(44,45)$. Initially, embryonic stem cells were modified through Cre-LoxP homologous recombination and injected in the pro-nucleus of wild-type mouse blastocysts, thus rendering embryonic stem cells as a necessary prerequisite for the generation of genetically engineered mouse models. Consequently, sequential breedings were required until the animals contained mutant alleles (46), supporting germ-line transmission. It should be noted that the time for the generation of modified mice was approximately 9-12 months, while the insertion of multiple alterations was associated with a number of technical difficulties. In other words, the entire process was time-consuming, costly and in some cases, uncertain.

In contrast to classical methods, the CRISPR system enables the elucidation of tumorigenesis networks and abolishes the need for embryonic stem cells or time-consuming 
Table III. Modeling of cancer mouse models through the CRISPR system.

\begin{tabular}{|c|c|c|c|c|}
\hline Cancer type & Mouse models & Modifications & Authors/(Refs.), year & Journal \\
\hline $\begin{array}{l}\text { Lung } \\
\text { adenocarcinoma }\end{array}$ & $\begin{array}{l}\text { CD1 and } \\
\text { C57BL/6J (B6) }\end{array}$ & $\begin{array}{l}\text { Eml4-Alk } \\
\text { translocation }\end{array}$ & Maddalo et al (56), 2014 & Nature \\
\hline Lung adenocarcinoma & $p 53^{+/-}$or $p 53^{-/-}$ & $\begin{array}{l}\text { Eml4-Alk } \\
\text { translocation }\end{array}$ & Blasco et al (55), 2014 & Cell Reports \\
\hline Lung adenocarcinoma & $\operatorname{Kras}^{\mathrm{LSL}-\mathrm{G} 12 \mathrm{D}-\mathrm{I}_{+}}$ & Nkx, Pten, Apc & Sanchez-Rivera et al (61), 2014 & Nature \\
\hline Liver cancer & $\mathrm{FVB} / \mathrm{NJ}$ mice & p53,Pten, Ctnbl & Xue et al (47), 2014 & Nature \\
\hline $\begin{array}{l}\text { Pancreatic ductal } \\
\text { adenocarcinoma }\end{array}$ & $\begin{array}{l}\text { Kras }^{\mathrm{LSL}-\mathrm{G} 12 \mathrm{D}-/+} ; \\
\mathrm{R} 26^{\mathrm{LSL}-\mathrm{Tom}} \\
H 11^{\mathrm{LSL-Cas9-/+}}\end{array}$ & $L k b 1$ & Chiou et al (62), 2015 & Genes and Dev. \\
\hline $\begin{array}{l}\text { Pancreatic ductal } \\
\text { adenocarcinoma }\end{array}$ & $\begin{array}{l}\operatorname{Kras}^{+/ L S L-G 12 D} \\
\operatorname{Trp} 53^{\operatorname{lox} / \text { loxP }}\end{array}$ & $p 53$, Kras and $p 57$ & Mazur et al (233), 2015 & $\begin{array}{l}\text { Nature } \\
\text { Medicine }\end{array}$ \\
\hline Medulloblastoma & C57BL/6N mice & Ptchl & Zuckermann et al (48), 2015 & $\begin{array}{l}\text { Nature } \\
\text { Communications }\end{array}$ \\
\hline Glioblastoma & Crl:CD1 (ICR) mice & Trp53, Pten, Nf1 & Zuckermann et al (48), 2015 & $\begin{array}{l}\text { Nature } \\
\text { Communications }\end{array}$ \\
\hline Breast cancer & $\begin{array}{l}\text { WapCre; } C d h 1^{\mathrm{F} / \mathrm{F}} ; \\
\text { Collal } 1^{\text {invCAG-AktE17K-IRES-Luc/+ }}\end{array}$ & $\begin{array}{l}\text { Cdh1, Akt-E17K } \\
\text { or Pten }\end{array}$ & Annunziato et al (63), 2016 & $\begin{array}{l}\text { Resource/ } \\
\text { Methodology }\end{array}$ \\
\hline Breast cancer & $\begin{array}{l}\text { Mammary stem cell } \\
\text { (MaSC) organoid-based } \\
\text { approach }\end{array}$ & $\begin{array}{l}\text { Inactivation of } \\
\text { Ptpn } 22 \text { or Mll3 }\end{array}$ & Zhang et al (234), 2016 & Cell Reports \\
\hline $\begin{array}{l}\text { Ovarian high-grade } \\
\text { serous carcinoma } \\
\text { (HGSC) }\end{array}$ & $\begin{array}{l}\text { Double } \operatorname{Trp} 53^{-/-} \\
\text {Brca }^{-/-} \text {mutant } \\
\text { mice }\end{array}$ & $\begin{array}{l}\text { Deletion at } p 53 \\
\text { and Brac2 genes }\end{array}$ & Walton et al (235), 2016 & $\begin{array}{l}\text { Cancer } \\
\text { Research }\end{array}$ \\
\hline $\begin{array}{l}\text { Invasive lobular } \\
\text { breast carcinoma } \\
\text { (ILC) }\end{array}$ & $\begin{array}{l}C d h 1^{\mathrm{F} / \mathrm{F}} ; \text { Pten }^{\mathrm{F} / \mathrm{F}} \\
\text { mice }\end{array}$ & $\begin{array}{l}\text { Ablation of Pten } \\
\text { expression through } \\
\text { CRISPR and lentivirus } \\
\text { in mammary glands } \\
\text { of mice with } \\
\text { loss of E-cadherin }\end{array}$ & Annunziato et al (63), 2016 & $\begin{array}{l}\text { Genes and } \\
\text { Development }\end{array}$ \\
\hline
\end{tabular}

mouse breeding. The CRISPR system emerges as a reliable and powerful tool for the creation of mouse models that harbor multiple oncogenic alleles, at a low cost. With this technological approach, various gene networks can be targeted simultaneously, allowing researchers to study the synergistic or antagonistic effects of genes in tumor initiation and progression in an accurate and effective manner. The CRISPR system appears to be a major contributor to the design of mouse models (Table III), given that CRISPR technology can simulate the genetic heterogeneity of the cancer genome by creating indels, point mutations, large deletions, large insertions and chromosomal rearrangements.

The CRISPR system is invaluable in mutating, deleting, inserting or translocating genes. Several research groups have produced extraordinary results in the field of mutagenesis via the CRISPR approach. For example, in the modeling of hepatocellular carcinoma, one group managed to create a frameshift truncation at two genetic loci through the hydrodynamic injection of plasmids encoding Cas9 nuclease and
sgRNAs (47), while another research group managed to generate oncogenic point mutations in the CTNNB1 gene with the use of homology-directed repair at DSBs induced by Cas9 (39). Of note, the former researchers demonstrated the desired modification of the phosphatase and tensin homolog (Pten) or p53 gene (tumor suppressor genes), alone or in combination, in 20 to $30 \%$ of mouse hepatocytes. Following the inoculation of Cas9 and sgRNAs, the authors demonstrated indel mutations in the Pten and $p 53$ genes at low efficiencies of 4 and $6.4 \%$, respectively. Thus, it was shown that it is possible to disrupt gene expression in two major suppressor genes, causing hepatocellular carcinoma. The study produced an accurate and reliable model of hepatocarcinogenesis, equal to that provided by Cre-LoxP recombination (47). Similarly, gain of function mutations in oncogenes, such as the Catenin b1 gene $(C t n n b 1)$ were conducted at $0.5 \%$ efficiency (47). Another example was illustrated through the CRISPR system-mediated abnormal gene expression of tumor suppressor genes (Ptchl, Trp53, Pten and Nf1), ultimately causing medulloblastoma or 
glioblastoma (48). Based on these results, it appears that the CRISPR approach allows the genetic engineering of oncogenes and tumor suppressor genes in specific somatic cells simultaneously, despite the low efficiency.

In general, specific nucleotide modifications or small deletions have been conducted with the use of the CRISPR system $(31,37)$, thus simulating the conditions that characterize specific human diseases. The CRISPR system has been confirmed to be invaluable in cancer research, due to its ability to generate cancer mouse models harboring multiple mutations simultaneously (49,50). For example, Findlay et al exploited the properties of Cas 9 nuclease to create mouse models with distinct combinations of genetic alterations (51).

When it comes to introducing large deletions, classical methods have, in most cases, proven to be insufficient due to the many recombination events occurring in embryonic stem cells (52). By contrast, eliminating large chromosomal regions became very simple with the use of the CRISPR system, as indicated by the results of two research groups. Specifically, Yang et al introduced Cas9 mRNA and four sgRNAs into murine zygotes in one step, producing mice with fluorescent tags into the following genes: Nanog, Sox2, Oct4 (essential stem cell genes) and Mecp2 (which causes Rett syndrome). When Cas9 nuclease mRNA and two sgRNAs were specifically used against the Mecp 2 gene, a 700 bp deletion was created (31). Additionally, the generation of germline CRISPR mice was accelerated by injecting CRISPR components in one-cell-stage embryos, as opposed to using embryonic stem cells, as validated by Krishnaswamy et al (53). The CRISPR system also proved to be very efficient inreplacing large ablated genomic region (exons 10-14) of dedicator of cytokinesis $8\left(\right.$ DOCK8) in Nlrp10 deficient mice (Nlrp10 $\left.{ }^{-/-}\right)$, thus restoring the dynamics of the immune cell cytoskeleton and the dendritic cell migration, which in turn orchestrate the immune response (53). When it comes to introducing large insertions at precise locations, insertion of large DNA sequences has also been accomplished through homologous directed repair mechanism in combination with the CRISPR system and fluorescent tags (31).

Nonetheless, the CRISPR system does not only induce targeted genetic alterations, but it can also be exploited for the evaluation of nonsense mutations involved in tumorigenesis, as indicated by Billon et al (54). Similarly, Billon et al presented a further advancement of the CRISPR system, fusing Cas9 nickase to base editor and constructing specific sgSTOP to mediate the transition of (CAA, CAG, CGA, TGG) codons located in the window of PAM into stop codons. The whole process was evaluated by restriction fragment length polymorphism (RFLP), through which the disruption of restriction enzyme recognition sites was verified (54). As a result, one can monitor the presence of cancer-related nonsense mutations in a considerable proportion (97-99\%) of the eukaryotic genome in eight species.

Furthermore, the CRISPR system has played a fundamental role in the production of chromosomal rearrangements that are implicated in cancer progression either as 'driver' or 'passenger' alterations. The tumorigenic process is influenced not only by the presence of mutations in oncogenes or tumor suppressor genes, but also indirectly by the presence of 'passenger changes'. For example, Torres et al accomplished the introduction of chromosomal translocation $\mathrm{t}(11 ; 22) / E S W R 1-F L I 1$ at percentages of 1.76 and 0.15 in 293 cells and human primary mesenchymal stem cells, respectively, using Cas9 nuclease and its related sgRNAs (32). In addition, the chromosomal translocation $\mathrm{t}(8 ; 21) / R U N X 1-E T O$ was introduced into 293 cells and $\mathrm{CD} 34^{+}$human hematopoietic progenitor cells with the use of the CRISPR system, successfully recapitulating the phenotype of acute myeloid leukemia (AML). Three other research teams used the CRISPR approach to introduce the lung oncogenic gene rearrangement that results in the echinoderm microtubule associated protein like 4-anaplastic lymphoma kinase (Eml4-Alk fusion protein). Specifically, Blasco et al used intratracheal or intrapulmonary lentiviral delivery of CRISPR components to trigger the oncogenic rearrangement between the Eml4 and Alk genes, located in chromosome 17 (55). Similarly, Maddalo et al (56) and Nishio et al (57) introduced the same oncogenic rearrangement using adenoviral delivery. In all of these studies, the experimental mice harboring the Eml4-Alk inversion appeared to display all the symptoms of non-small-cell lung cancer (NSCLC) (56) and exhibited high sensitivity to ALK inhibitors, such as crizotinib (57). In a similar setting, the CRISPR system was used to introduce the KIF5B-RET or EML4-ALK inversion (35), thus demonstrating that the proximity of two loci, in which a chromosomal rearrangement takes place, determines the capacity of the CRISPR system to reach its maximum efficiency. Last but not least, Ghezraoui et al successfully introduced the anaplastic large cell chromosomal translocation $\mathrm{t}(2 ; 5) / N P M-A L K$ using classical Cas 9 nuclease or paired Cas 9 nickases (21). Cas 9 nickases are distinguished from classical Cas9 nickases due to one of the endonuclease domains being inactivated by a mutation, which in turn confers additional efficiency.

Although the CRISPR system has been applied both to 'in vitro' and 'in vivo' biological systems, several difficulties are encountered when the Cas9 nuclease is delivered to the mitotic tissues of mice. The most common methods of transferring Cas9 along with sgRNAs consist of viral vectors (lentivirus, adenovirus and adeno-associated virus); even though adenoviruses have high packaging capacity, thus being able to deliver large genomic sequences (such as that of Cas9) (58), they may cause high immunogenic reactions independently of cell type (59). This has led to a combination of the CRISPR system and Cre-LoxP recombination technique in the study of the networks implicated in tumorigenesis (42). Specifically, Cre-dependent Cas 9 knock-in mice have been created via incorporation of a flanked Cas9 expression cassette (Cre-dependent CAG-LSL-Cas9) upon the exposure of strong CAG promoter into the Rosa26 locus, without the need to package Cas9 into viral particles and the accomplished inducible expression of Cas 9 mediated by Cre recombinase. The generation of Cre dependent Cas9 knock-in mice was the result of using the above-mentioned procedure in embryonic stem cells that were transplanted into the blastocysts of C57BL6/J mice. In turn, the Cas9 knock-in mice were transduced with a cassette containing suitable sgRNAs, orientated towards specific yet multiple genetic loci in conjunction with the sequence of Cre recombinase (42). This combination of Cre recombinase and Cas 9 nuclease was used to introduce loss of function mutations in tumor suppressor genes $p 53$ and $L k b l$ and a gain of function mutation (KRASG12D) in the 
Kras lung gene, given that these genes are regarded 'the driver cancer genes' by the CGA Network (60). At the same time, it was shown that the introduction of loss of functional mutations in NK2 homeobox 1 (Nkx2.1), Pten and adenomatous polyposis coli $(A p c)$ genes with the CRISPR system allows for the creation of mouse models of lung adenocarcinoma with deficient p53 expression or heterozygous expression of Kras gene $\left(\right.$ Kras $\left.^{\text {G12D-/+ }}\right)$ through Cre-LoxP recombination (61). Thus, the CRISPR system was proven to be functionally significant in elucidating the putative drivers of signal transduction pathways in established mouse models of cancer. In addition, Chiou et al constructed $H 11^{\text {LSL-Cas9/+ }}$ mice, by inserting the Cas9 cassette with a flanked stop region (Loxp-STOPLoxp) into the H1l locus of mice and they were crossed with CMV-Cre deleter mice, demonstrating constitutive expression of Cas9 due to the recombinase action of Cre. Following this, $H 11^{\text {LSL-Cas9/+ }}$ mice were crossed with $\mathrm{Kras}^{\mathrm{LSL}-\mathrm{G} 12 \mathrm{D} /+}$; $\mathrm{R} 26^{\mathrm{LS}}$ (KT) mice, generating KT; $H 11^{\mathrm{LSL}-\mathrm{Cas} 9 /+}$ mice. The latter were infected with Lentivirus-sg $L k b l / C r e$ with an ubiquitous promoter, accomplishing the disruption of pancreatic Lkb1 expression in adult pancreatic cells 'in vivo', and thus simulating stages of pancreatic cancer progression (62). Elsewhere, Annunziato et al performed a $C d h l$ gene deletion by encoding E-cadherin through Cre-LoxP recombination in mammary epithelium, with the concomitant disruption of Pten by the CRISPR system. Unexpectedly, the authors observed an increased immune response following the exposure to Cas9 (63).

\section{Germ-line gene editing through the CRISPR system}

Apart from the wide spectrum of genetic alterations, the CRISPR system holds considerable potential as a tool that can be applied to either embryonic stem cells or other types of stem cells, surpassing somatic mosaicism that is commonly found when genetic modifications are performed in zygotes. Genetic mosaicism has been attributed to the slow rate of Cas9 nuclease mutagenesis and the discordance between transcription and translation. Characteristically, it has been mentioned that the translation of Cas9 mRNA occurs until the first cell division (64). Therefore, the CRISPR system has been applied to embryonic stem cells for the generation of conditional knock-out mice. For example, Flemr et al transduced mouse embryonic stem cells with a vector expressing bacterial BirA ligase in a constitutive manner, driven by the promoter of the Rosa26 locus; at the same time, the cells were enriched with Cas9, a single-strand oligonucleotide containing the FLAG-AviTag sequence that could be biotinylated by BirA ligase and a recombination reporter equipped with (pRR-Puro) selection marker which was activated following homology recombination events (65). Thus, they established a straightforward and flexible method for accelerating the production of conditional deficient mice inessential genes, tracing endogenously the biallelic deficient cells without using selection markers (65). More importantly, they excluded the possibility that the phenotypes of deficient mice could be the result of non-targeted system efficacy.

The targeted disruption of gene expression at both alleles of genes Tetl, 2 and 3 in zygotes with $20 \%$ efficiency has been previously demonstrated (37). Following this, researchers attempted to disrupt the expression of five genes (Tet1, 2, 3, Sry and Uty); however, the elimination efficiency appeared to below, with the genetically modified cells constituting only $10 \%$ of the total population. On the other hand, Wang et al (37) produced impressive results by introducing Cas9 nuclease with the appropriate sgRNAs in the germ-line of mice, thus managing to genetically manipulate Tet genes without the need for embryonic stem cells. Notably, the sgRNA can be delivered either as plasmid or single-strand RNA (ssRNA), while Cas9 nuclease can be packaged as plasmid, mRNA or protein. In the former approach, a concomitant introduction of Cas 9 and a single sgRNA for each Tet gene produced $89 \%$ of mice harboring the anticipated genetic alterations (37). In the second approach, the targeting of Tet1-2 genes with the use of sgRNAs proved that mutations in both genes occurred at a percentage of $70 \%$. In the third approach, a complex comprising Cas9 mRNA, sgRNA and single-strand DNA harboring the desirable change was used, resulting in $60 \%$ of the produced mice harboring one mutation and $7 \%$ of the mice carrying a combination of two different genetic alterations.

In the context of hematological malignancies, the proposed methodology includes the editing of progenitor cells 'ex vivo' and their subsequent delivery into the syngeneic recipient (66-68). Hematopoietic cells have the unique capacity of expanding after being re-injected into the human body. For example, Heckl et al generated mouse models of AML by simultaneously altering a couple of genes in hematopoietic stem and progenitor cells (67). In the same context, another research team eliminated the tumor suppressor gene, mixed lineage leukemia 3 (Mll3; also known as $K m t 2 c$ ), in primary mouse hematopoietic progenitor cells (HSPCs) of the shNf1 genotype; $\operatorname{Tr} 553^{--}$cells that were transplanted in AML (68). Impressively, it was shown that Mll3 haploinsufficiency acts as secondary determinant factor in the progression of leukemogenesis (68). Mll3 mutant mice alone did not exhibit any signs of leukemia, while mice harboring Mll3 mutations developed ureter epithelial tumors in $p 53^{+/-}$genotype (68).

Other studies have also documented the therapeutic efficiency of the CRISPR system 'ex vivo' in the setting of E $\mu$-Myc lymphomas (66). Heckl et al devised a series of sgRNAs against eight candidate genes usually implicated in myeloid cancers, thereby recapitulating the proposed genetic networks and the mutations responsible for disease progression and outcome (67). Specifically, the primary HSPCs harboring a knock-in Flt3 internal tandem duplication (Flt3-ITD) were edited for five characteristic genes. These genes were either epigenetic modifiers, transcription factors or mediators of cytokine signaling and were as follows: Tet2, Dnmt3a, Runxl, Nf1, Ezh2, Smc3, p53 and Asxl1. The selected genes were modified to simulate the genetic networks responsible for the phenotype of myeloid malignancies (67).

Similarly, Zhong et al presented an innovative method for genetically manipulating AG-haESCs harboring a disruption at two distinct DNA methylated regions (H19 and Gtl2), thus providing evidence for the generation of live embryos following AG-haESC injection into mature oocytes. Of note, the authors demonstrated that the CRISPR genome editing tool successfully introduced genetic modifications in AG-haESCs, thus allowing genetic screening in haploid cells in a simple and rapid manner (69). 
Table IV. Therapeutic approaches of the CRISPR method in a wide range of genetic diseases.

\begin{tabular}{|c|c|c|c|c|}
\hline Disease gene & Target & Concept & Substrate & Authors/(Refs.), year \\
\hline Hemophilia A & $h F 8$ & $\begin{array}{l}\text { NHEJ-mediated } \\
\text { correction of inversion }\end{array}$ & Patient iPSCs & Park et al (70), 2015 \\
\hline$\beta$-thalassemia & $H B B$ & $\begin{array}{l}\text { Cleave the endogenous } \\
\beta \text {-globin gene (HBB) }\end{array}$ & $\begin{array}{l}\text { Tripronuclear } \\
(3 \mathrm{PN}) \text { zygotes }\end{array}$ & Liang et al (236), 2015 \\
\hline$\beta$-thalassemia & $H B B$ & HDR-mediated correction & Patient iPSCs & Xie et al (74), 2014 \\
\hline Cysticfibrosis & CFTR & $\begin{array}{l}\text { HDR-mediated correction } \\
\text { of CFTRdeltaF508 mutation }\end{array}$ & PatientiPSCs & Firth et al (83), 2015 \\
\hline Cysticfibrosis & CFTR & HDR-mediated cDNA knock-in & Intestinal organoid & Schwank et al (82), 2013 \\
\hline Cataract & Crygc & HDR-mediated correction & Zygote, mouse SSC & $\begin{array}{l}\text { Wu et al }(84), 2013 \\
\text { Wu et al }(85), 2015\end{array}$ \\
\hline Huntington disease & $H T T$ & NHEJ mediated allele editing & & Monteys et al (78), 2017 \\
\hline Hereditary tyrosinemia I & Fah & $\begin{array}{l}\text { HDR mediated point } \\
\text { mutation of Fah gene }\end{array}$ & Adult tissue cells & Yin et al (39), 2014 \\
\hline Cardiovasculardisease & Pcsk9 & $\begin{array}{l}\text { NHEJ-mediated } \\
\text { disruption of PCSK } 9\end{array}$ & Adult tissue cells & Ding et al (58), 2014 \\
\hline
\end{tabular}

\section{CRISPR system: A therapeutic tool in a wide range of genetic diseases}

With the prospect of personalized therapy, the gene editing of iPSCs has drawn a surge of interest in a wide range of diseases. The reasons behind this lie in the capacity of the cells to divide unlimitedly, while maintaining their genome integrity and their differentiation capacity into three different cell layers (endoderm, ectoderm and mesoderm). Notably, the use of iPSCs for the generation of modified cell lines appears to provide further insight into the underlying molecular mechanisms of each disease. Therefore, the autologous transplantation of iPSCs appears to be a promising therapy in personalized medicine, and the use of iPSCs in the CRISPR approach holds promise for the field of genetic diseases (Table IV).

Initially, Park et al supported that the CRISPR system can remodel the large inversions that are encountered in introns of blood coagulation factor VIII in hemophilia. The researchers corrected the mutations of the $F 8$ gene in patient endothelial cells which were propagated by iPSCs. The correctness and accuracy of the CRISPR system was validated from the fact that hemophiliac mice were rescued upon the engraftment of corrected iPSCs (70).

In the frame of genetic diseases, gene correction seems to be very beneficial in hemoglobinopathies, such as sickle cell disease (SCD) and $\beta$-thalassemia. In the context of SCD, the causal origin of the disease is a replacement of valine with glutamate due to a homozygous missense point mutation in the hemoglobin subunit beta $(H B B)$ gene, which results in the accumulation of hemoglobin and the circulation of red blood cells with conformational changes. The correction of mutated sickle cell gene expression was accomplished with the use of the CRISPR system in iPSCs derived from patients, followed by their differentiation into functional erythrocytes $(71,72)$. It was shown that Cas9 nuclease was superior to ZNF in modulating the expression of the sickle gene (73). The benefit of the CRISPR system on SCD has also been demonstrated in a clinical trial (NCT03167450).

In the case of $\beta$-thalassemia, iPSCs have been shown to differentiate into specific lineages, thereby presenting as a possible therapeutic means (74). Similarly, the hemoglobin subunit beta $(H B B)$ gene has been effectively engineered by the CRISPR approach in tripronuclear zygotes, at a $15 \%$ rate, considering that the mutations in the human $H B B$ gene are believed to be responsible for the disease. However, the low effectiveness of the CRISPR approach highlighted the need for precise optimization in a clinical setting.

In the field of gene editing, a potential obstacle is the immune rejection of 'ex vivo' modified cells that carry newly expressed or corrected proteins. The infusion of modified cells harboring new proteins can evoke the stimulation of the immune system, recruiting cytotoxic $\mathrm{T}$ lymphocytes in exhausting the potential 'enemy'. In another case, it has been shown that neutralizing antibodies can arise against replacement blood clotting factors in patients with hemophilia (75). However, the possibility of inducing an immune reaction has been avoided with the CRISPR system, particularly if one considers that the gene therapy of SCD has been achieved without adverse effects. Specifically, autologous hematopoietic stem cells (CD34 ${ }^{+}$cells) have been transduced with lentiviruses expressing the modified globin gene, leading to the rescue of the phenotype at the patient level. In other words, by exploiting the CRISPR gene engineering tool, it was possible to alleviate the symptoms of the disease.

As regards Huntington's disease (HD), previous RNA interference-based method reduced the expression of the Huntingtin gene (HTT), but did not manage to completely attenuate gene expression, as anticipated (76). By contrast, the CRISPR system proved to be invaluable in eradicating the expression of HTT, if one considers that the origin of 
HD is ascribed to CAG repeat expansion at the 1st exon of HTT. Therefore, using the CRISPR system, researchers have managed to disrupt the sequence of the mutant HTT allele (77), while at the same time another research team highlighted the ablation of HTT gene expression both in patients and in a transgenic mouse model bearing the human HTT, using the CRISPR system (78). In the latter case, they characteristically created small deletions and produced single nucleotide polymorphisms (SNPs), which altered the determinant PAM sequence ('NGG'), increasing the effectiveness of Cas9 nuclease. In both cases, the researchers used the CRISPR strategy to cure HD. In parallel, iPSCs derived from patients with HD were repaired with the aid of the CRISPR and the piggyBac transposon-based approach (79). In addition, in the case of neurogenerative diseases, such as Parkinson's disease, iPSCs have been employed to differentiate into neurons and have been used as a substrate of the CRISPR screen for the identification of activators of toxic protein a-Synuclein (aSyn) (80). In the frame of inheritable genetic disorders, the CRISPR approach has also been shown to mediate the repair of dystrophin gene mutations in zygotes of mdx mice (C57BL/10ScSn-Dmdmdx/J) at 2\% efficiency (81).

Of note, the CRISPR approach has been used as an exciting therapeutic technological tool for the treatment of cystic fibrosis. Cystic fibrosis essentially constitutes a disease that is the outcome of many genetic alterations encountered at the CF transmembrane conductor receptor (CFTR). Organoid buds from iPSCs derived from patients with cystic fibrosis have been successfully modulated by the CRISPR system, holding great promise for organ transplantation and gene therapy (82). The correction of the CFTR locus was performed in a separate case, generating iPSCs with the correct allele of CFTR, as demonstrated by Firth et al (83). In parallel, the efficiency of the CRISPR genome engineering tool has been verified in organoids derived from patient intestinal stem cells, where the mutation (Phe 508) of the CFTR was repaired (82). It should be mentioned that the elimination of the side-effects caused by the $C F T R$ mutation was verified via normal secretory functions (82). Apart from the repair of the CFTR locus in stem cells of various origins, studies have supported the CFTR gene editing in one step, upon influx of the CRISPR system in zygotes. In such cases, an oligonucleotide of wildtype $C F T R$ sequence is inserted as a donor template and used by the Cas9 nuclease via homologous recombination (84). The results were profoundly spectacular due to germ-line transmission of the repaired CFTR locus allele, even though off-target mutagenesis remained a possibility. Nonetheless, the danger of insertional mutagenesis in murine germ-line cells was abrogated by engineering the mutant loci at spermatogonial stem cells (SSCs). Wu et al reported that the mutational repair of the EGFP transgene or endogenous Crypc gene via the CRISPR approach in SSCs that were competent to form male gametes after injection into testes, resulted in the formation of round spermatids following fusion with mature oocytes (85). The major advantage of genetic manipulation via the CRISPR approach in SSCs, as compared to gene editing in zygotes, has been the lack of side-effects and the generation of anticipated descendants at $100 \%$ efficiency (85). Therefore, the CRISPR method has proven to be a promising approach for the treatment of genetic diseases.
In addition to the above-mentioned findings, Xie et al (86) demonstrated that the epigenetic dormancy of the FMRl gene was reversed using the revolutionary genome editing tool, CRISPR in iPSCs derived from patients or in somatic hybrid cell lines. The effect of Cas9 was directed to the removal of the CGG repeats that are encountered in the FMRI gene. Specifically, the researchers cleaved the FMRl gene repeats with high efficiency, inducing DSBs and using homologous recombination (86). The same genetic disorder was also reported to be repaired via NHEJ, albeit less efficiently (86). A landmark study by Horii et al successfully demonstrated the genetic correction of a mutation at the DNMT3B locus in iPSCs with the use of the CRISPR system, thus repairing a rare abnormality [termed immunodeficiency centromeric region instability facial anomalies syndrome (ICF)] (87). In the prospect of curing human severe immunodeficiency, researchers observed that iPSCs deficient for JAK3 perished during the initial stages of the disease due to a low BCL2 expression pattern; nonetheless, the correction of the JAK3 mutation with the CRISPR approach caused iPSCs to differentiate into fully functional $\mathrm{T}$ cells, including the full spectrum of $\mathrm{T}$ cell receptors (TCRs) (88). Consequently, the combination of the CRISPR approach and iPSCs has been reported to be particularly beneficial in chronic granulomatous disease (CGD), where patients suffer from the accumulation of oxidative molecules that are used as a phagocytic weapons against fungi and bacteria (89).

Furthermore, patient-derived pluripotent stem cells have been exploited by the CRISPR method for therapeutic intervention in other diseases, such as Fanconi anemia (90), dominant dystrophic epidermolysis bullosa (91), retinitis pigmentosa (92) and severe cases of retinal dystrophy [Leber congenital amaurosis-10 (LCA10)] (93).

Finally, the CRISPR system has been highlighted as a unique system with profound impact on repairing gene mutations in adult tissues 'in vivo'. Yin et al (39) rescued the phenotype generated by Fah gene deficiency via repairing of the Fah mutation in hepatocytes using the CRISPR system. Notably, Cas9 nuclease mediated its beneficial action by restoring the function of hepatocytes at very low (0.4\%) efficiency in mouse models harboring hereditary tyrosinemia (39). Despite the initial effectiveness of the genome engineering tool being very low, it was culminated over time, repairing $33 \%$ of deficient hepatocytes. In another experimental setting, the disruption of Pcsk9 gene expression in the liver resulted in an attenuation of the concentration of LDL-C, which would otherwise be very harmful for the heart (58).

As a general note, it has been claimed that the Cas9 nuclease constitutes a therapeutic model for the treatment of several genetic disorders. In the case of monogenic recessive disorders, such as cystic fibrosis, sickle-cell anemia, hereditary tyrosinemia or Duchenne muscular dystrophy, the target mutation can be repaired with the aid of Cas9. In this manner, the protein derived from the corrected gene can be developed in native conditions. In the case of dominant-negative disorders where the target gene is represented by one allele (haploinsufficiency phenomenon), the CRISPR system seems to be the most advantageous method in inactivating the mutated allele. Alternatively, the use of inactivated Cas9 fused to a transcriptional repression domain can be used to rescue the 
phenotype (94). In addition, the elimination of duplicated regions could be accomplished through Cas9 nuclease and NHEJ-mediated repair, whereas therapeutic benefit has also been observed by introducing protection mutations in mitotic tissues in complex diseases. Finally, the CRISPR system has been employed in the modification of T cells, particularly with chimeric antigen receptor (CAR) or artificial TCRs, prior to introducing them into the body of cancer patients (95) (Fig. 3).

\section{Organoids: Smart weapons against complex genetic diseases}

A significant part of the research community has focused on the generation of the reliable biological models (animal and cell lines) that will be able to mimic all the characteristic mechanisms of cancer cells with high fidelity. In many cases, the complete understanding of the genetic perturbations involved in cancer outgrowth has been accomplished; however, researchers have been unable to directly modify genes in the human body, thus resulting in a highly anticipated therapeutic strategy (96).

Despite the successful creation of GEMMs, there is significant shortage of therapeutic applications, mainly due to difficulties in the isolation of specific neoplastic cells from the multitude of extended stromal compartments in animal models. The scarcity of therapies can also be explained by the fact that animal models are time-consuming and costly. Cancer cell lines, on the other hand, are known to harbor genetic profiles that are not identical to the initial tumor mass and are cultured in two-dimensional directions. Furthermore, cancer cell lines are uncoupled to the amount of non-neoplastic cells, which are usually located in the tumor microenvironment (97). As a consequence of the above, organoids have been postulated as a novel facile tool that holds great promise in the field of cancer research. Tumor-derived organoids can mimic all the typical characteristics of the initial tumor mass, the three-dimensional (3D) structural framework and the property for uncontrolled growth. It has therefore been shown that organoids can not only recapitulate the genetic modifications that arise in cancer cells with high fidelity (98), but can also provide unique opportunities for the generation of fully characterized models at an unprecedented rate.

Hans Clevers and colleagues were the pioneer investigators in the field of organoids, as they managed to create intestinal epithelial organoids with distribution of all cell types (such as stem, goblet and villus cells), maintaining the procedures of cell division and differentiation in physiological conditions [Sato et al (99)]. Hans Clevers supported that organoids are able to efficiently simulate the tissue microenvironment, as represented by their structural and functional hallmarks (100). Lancaster and Knoblich, on the other hand, defined an organoid as a 3D structure in which progenitor cells are selforganized in order to commit to specific cell lineages, in a manner which is consistent with the 'in vivo' conditions (101). Characteristically, the cells of organoids have internal gates of self-assembling and self-regulation, even though their manipulation is not restricted to exogenous signals.

The origin of organoids can be either embryonic or adult stem cells or patient-derived stem cells (100). On the one hand, organoids derived from stem cells can be crucial to the study of organ development or organ pathologies (101). While pluripotent stem cell-based organoids exploit developmental processes, adult stem cells can be coerced to form organoids by creating conditions that mimic the stem cell environment during physiological tissue self-renewal or during DNA damage/repair (102). On the other hand, patient-derived organoids can be used to gain drug-response feedback in patients. Tumor organoids display a differential mutational landscape indicative of each parental tumor. The feasibility of culturing solid tumors directly from the patient in the form of organoids holds great promise (102).

From a functional aspect, the generation of human organoids is regarded highly important, as it has the potential to enable the study of human pathogenesis 'in vitro'. For example, murine neoplastic organoids have been generated from $\mathrm{Kras}^{+/}$ LSL-G12D; $P d x l$-Cre mice ('KC mice') in order to recapitulate the phenotype of human preinvasive pancreatic intraepithe-

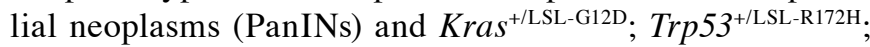
$P d x 1$-Cre mice ('KPC mice') (103). It was demonstrated that many candidate driver genes of the neoplastic procedure are represented in the proteomic and transcriptional genetic profile of murine pancreatic ductal organoids (103). The functional significance of organoids was demonstrated when human tumor organoids were engrafted into immunocompromised $(\mathrm{Nu} / \mathrm{Nu})$ mice, thus highlighting the presence of the stromal compartment and validating the accuracy of pancreatic tumorigenesis through organoids (103).

Nonetheless, the use of organoids is not restricted to the study of molecular mechanisms that drive developmental processes $(104,105)$, but may also be used for the modeling of diseases (Fig. 4). At the same time, the generation of patient-derived organoids can serve as an 'ex vivo' rational platform that has the potential to predict the patient response to specific drug administration, thereby helping towards deciding on the appropriate patient treatment individually, particularly if one considers that the majority of organoids are amenable to pharmacological studies (Fig. 4). For example, van de Wetering et al used patient-derived organoids as a potential model to simulate the networks that characterize intestinal diseases, submitted them in high-throughput drug screens, thereby investigating the interactions among target genes (106). Intestinal cancer organoids derived from 20 sequential colorectal carcinoma patients were employed to create a living colorectal biobank (106), given that conventional cancer cell lines do not represent the tissue structure and genetic characteristics of original neoplasms. Remarkably, the differential expression of parental intestinal neoplasms was well detected in colorectal organoids (106) and was shown that colorectal tumor organoids retained the molecular and histopathological features of original tumors, as well as their transcriptional profile. Importantly, van de Wetering et al demonstrated the existence of an association between drugs and the genomic profile of tumor organoids. Furthermore, $p 53$ gene-deficient tumor organoids appeared to be prone to treatment with the MDM2-inhibitor, Nutlin-3a, whereas organoids with the elimination of $R A S$ mutations were respectively sensitive to therapy with specific antibodies against epidermal growth factor receptor (EGFR) (106). Consequently, the pharmacodynamic profile of primary cancers, as well as of infectious and developmental diseases, has the potential to 


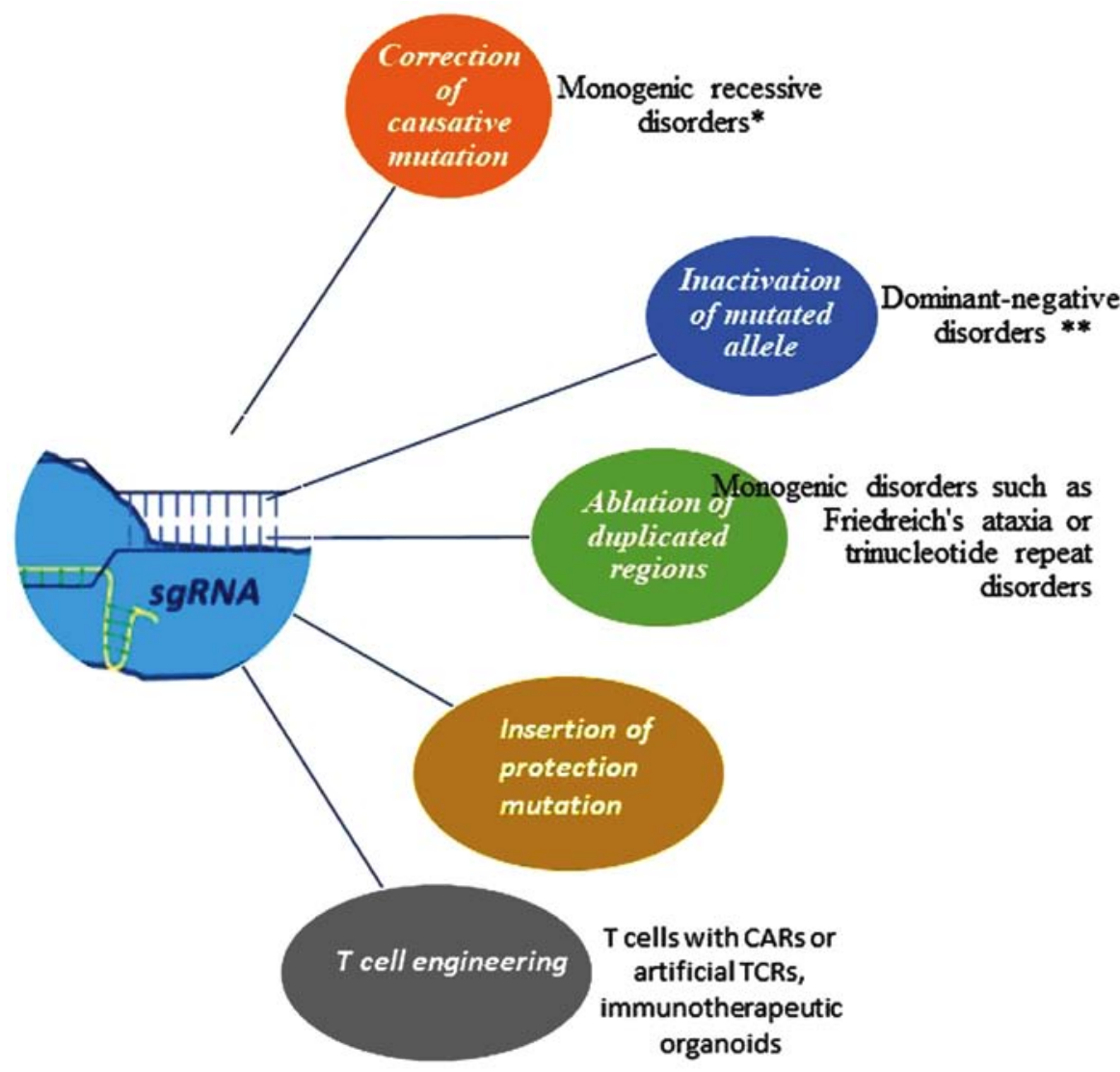

Figure 3. Cas9 nuclease as a therapeutic model for the treatment of genetic disorders. In the case of monogenic recessive disorders such as cystic fibrosis, sickle cell anemia, hereditary tyrosinemia or Duchenne muscular dystrophy, the target mutation is repaired with the aid of Cas9. In this manner, the protein derived from corrected gene can be developed in native conditions. In the case of dominant-negative disorders in which the target gene is represented by one allele (haploinsufficiency phenomenon), the CRISPR system seems to be the most advantageous method in inactivating the mutated allele. In other instances, the elimination of duplicated regions could be accomplished through Cas9 nuclease and NHEJ mediated repair, whereas therapeutic benefit has also been observed by introducing protection mutations in mitotic tissues in complex diseases. Finally, CRISPR system has been employed for the modification of T cells, especially with CAR or artificial TCRs, with the aim to introduce modified cells into the body of cancer patients. CRISPR, clustered regularly interspaced short palindromic repeats; Cas9, CRISPR-associated protein 9; NHEJ, non-homologous end joining; CAR, chimeric antigen receptor; TCR, T-cell receptor. The single asterisk (*) indicates cystic fibrosis, sickle cell anemia or Duchenne muscular dystrophy. The double asterisks (**) indicate transthyretin-related hereditary amyloidosis or dominant forms of retinitis pigmentosum.
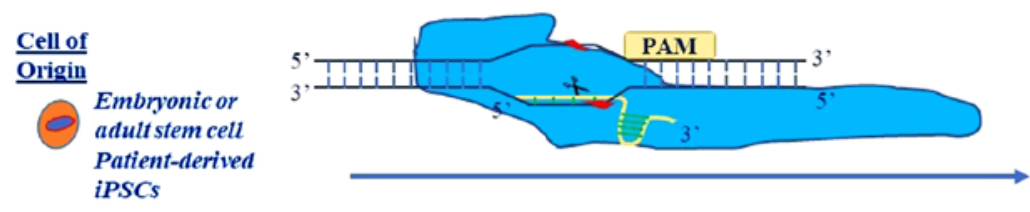
Modified cell through CRISPR approach

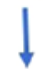

Chromosomal
translocation
Insertion
Deletion

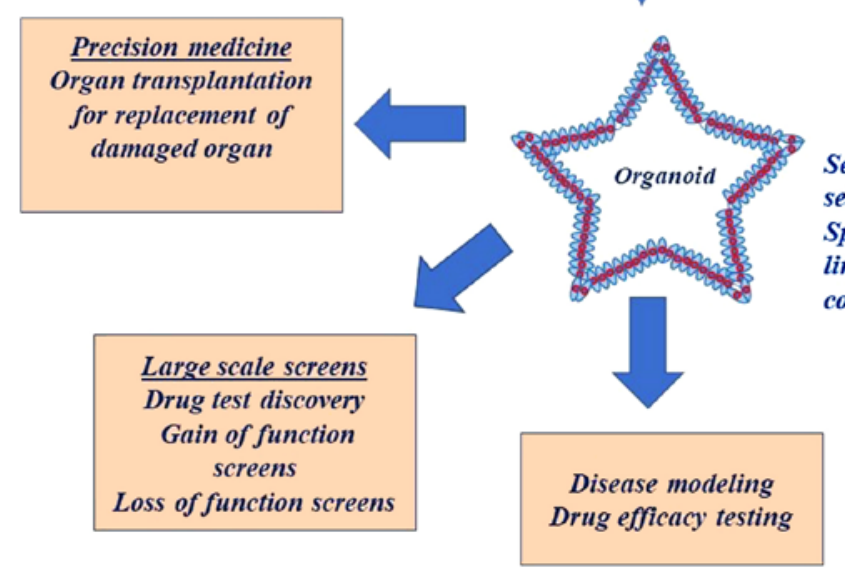

Self-assembling, self-regulation Spatially restricted lineage commitment

Figure 4. The use of CRISPR-edited organoids. CRISPR gene editing can be used to generate organoids for drug target validation, mechanistic analysis and patient stratification studies,as well as high-throughput pooled or high-content arrayed screens. CRISPR, clustered regularly interspaced short palindromic repeats; PAM, protospacer adjacent motif; iPSCs, induced pluripotent stem cells. 
be recapitulated from a colorectal biobank derived from organoids that have originated from patient biopsy samples, thus aiding in the conduction of personalized therapy that is pertinent to genes of drug sensitivity or resistance.

The potential use of organoids in the field of transplantation, as an alternative to iPSCs, holds immense promise. Organoids have been transplanted in an autologous manner without immunogenicity reactions, without the risk of teratomas and with assured stability (107). Notably, researchers have found the culture conditions for gastric (108), pancreatic (109), hepatic $(110)$, prostatic $(111,112)$ and intestinal organoids $(113)$. The ultimate goal is to replace damaged organs inpatients with organoids that do not harbor the usual genetic perturbations, given that the colonization of cancer organoids in the human body can contribute to metastasis $(60,114,115)$. A feasible personalized approach can be performed through the correction of genetic modifications by Cas9 nuclease in patient-derived organoids, and subsequently, the transplantation of these modified organoids into the bodies of patients. Nonetheless, the engraftment of organoids and the delivery of Cas9 nuclease and its components need to be further optimized, as thus far, the engraftment of organoids has been accomplished at only $1 \%$ efficiency, whereas a $10 \%$ efficiency is usually required for the replacement of determined protein elimination, as shown in the case of liver organoids (110).

From a therapeutic point of view, the use of organoids and their genetic manipulation through the CRISPR system is regarded extremely important in precision medicine. Recently, a colorectal tumor organoid library (CTOL) was constructed, encompassing 55 colorectal tumor organoids and 41 respective normal colorectal organoids (116), using the CRISPR approach. Fujii et al (116) demonstrated that the transition of carcinoma to more progressive stages was not associated with niche signals; at the same time, it was suggested that the mutations in oncogenic pathways are responsible for conferring the selective advantage of neoplastic growth, thus paving the way for the development of patient-specific therapies. Personalized therapy based on organoids seems feasible if one considers the reported mutations of the main five signaling pathways: WNT, RAS/mitogen-activated protein kinase (MAPK), phosphoinositide 3-kinase (PI3K), transforming growth factor (TGF) and p53 (60). The study by Fujii et al provided compelling evidence that tumor organoids and the CRISPR approach can be effectively used in xenotransplantation assays 'in vivo', thus bridging the gap between genetic profile and personalized medicine. Specifically, organoids were injected in splenic compartments or into renal cell types of NOG mice, demonstrating that the drivers of metastatic process are not related to mutations or niche requirements (116). Additionally, Fujii et al managed to modify genes of interest in organoids derived from patient colon tissue using the CRISPR approach, in an attempt to elucidate the functionality of intestinal cell types. Last but not least, the powerfulness of the CRISPR approach was confirmed by Drost et al (117), via sequential editing of genetic loci $A p c, p 53, K R A S$ and SMAD4 and converting normal colon organoids derived from human intestinal crypt stem cells to tumor organoids, without the need for stem-cell niche factors. Characteristically, it was shown that $A P C$ and $p 53$ deficiency can induce chromosomal instability and aneuploidy, i.e., characteristics of cancer. The efficiency of tumor organoids was mostly highlighted by the fact that they sustained their tumor heterogeneity upon engraftment into immunodeficient mice (117). The innovative results were attributed to the plasticity of stem cell organoids, which undoubtedly expand our understanding of the underlying molecular mechanisms responsible for colorectal carcinogenesis.

Overall, it is considered that organoids can function as smart weapons against many cancer types, by the release of soluble proteins with immunomodulatory activity or recombinant antibodies lacking Fc, with modified properties, thus circumventing the cytokine storm induced by the cross-reaction of cells bearing Fc receptors $(118,119)$. Thus, cells are precisely committed to continuously providing immunotherapeutic molecules against cancer. The rationale is based on allowing cells to be developed in a constrained and controlled environment, secreting therapeutic molecules when the cancer cells are present. For example, organoids constructed by mesenchymal stem cells have been mentioned to secrete interleukins (IL-2, IL-12), thus preventing the onset of melanoma $(120,121)$.

Even though tumor CRISPR-modified organoids hold great promise for gene therapy in a number of diseases, their use may be hindered by certain disadvantages, as shown in the case of intestinal tumor organoids. For example, drug sideeffects cannot be properly evaluated as intestinal organoids lack immune, nervous and vascular system $(122,123)$. In addition, heterogeneity is usually observed between human and murine organoids, which can be ascribed to the existence of secreted factors in the intestinal microenvironment, as for example epigenetic factors, hormones, etc. Finally, in certain cases, the composition of organoids is not consistent with the structure of cells naturally occurring in an organism (124).

\section{Applying bioengineering approaches and creating the appropriate niche to improve organoid-based therapies 'in vivo'}

Organoids, despite attempting to simulate the proxies of 'in vivo' tissues, they do not recapitulate the complexity of an organism. The whole procedure of generating organoids requires optimization at many levels. First of all, a specific extracellular matrix (ECM) is a prerequisite for various cell types, considering that the ECM is the driver of signaling and responsible for the structural landscape (125). Matrigel is usually used for the engraftment of stem cell-derived organoids; however, it is not sufficient in meeting the requirements in a cell type-dependent manner (126). Several approaches have been used for the deposition of specific ECM in various cell types, such as nanolithography, soft lithography, electron-beam, nano-imprint lithography, etc. (127), which mimic the basement membrane fibers. Another method for constructing natural organoids is to design surfaces that ensure the engagement of adhesion molecules. However, the regulation of signaling cues in a spatial-dependent manner poses a significant challenge when it comes to natural engraftment of organoids into organisms. The delivery of soluble growth factors with the use of nanoparticles or bioresponsive materials can confer the control of signal orchestration in a spatial-dependent manner (125). Finally, it should be taken 
into consideration that other cell types, such as immune and mesenchymal cells, can play a fundamental role in the successful engraftment of organoids, as it has previously been shown by Lindemans et al (128). In the same context, luminal cells have been shown to play a vital role in conducting the necessary interactions between microbial flora and epithelial cells, as well as cells of the epithelial layer (129).

\section{Towards personalized therapy}

The comprehensive understanding of the molecular alterations that have a profound impact on gene expression is essential in order to achieve personalized care for patients with neoplasia. Undoubtedly, personalized medicine has already been used by clinicians (130). The national scheme of clinical trials will enable clinicians to determine the appropriate drug administration for each patient individually and the CRISPR approach has the capacity to confer additional therapeutic benefit.

A recent study demonstrated that patient-specific therapy can bypass the drug resistance that is usually associated with lung cancer and is caused by tyrosine kinase inhibitors (TKIs) targeting against $E G F R$. Genomic mutations in EGFR (E19del, T790M at exon20 and L858R) have been highly associated with the drug resistance of lung tumors following the administration of TKIs, particularly the T790M mutation, which is found in $>50 \%$ of patients. In this context, Cas 9 nuclease emerges as a molecular scalpel that can modify the genome in such a manner that the outcome of the disease is improved in a personalized and permanent manner. The proposed proof of concept is the repair of the mutated EGFR gene, using Cas9 nickase. Specifically, Cas9 nickase can either induce singlestrand breaks and repair the mutated gene via homologous recombination (HDR), or decay the mutated EGFR. It has been postulated that CRISPR component assembly can be achieved in plasmids and delivered intratracheally or intravascularly in some cases (131).

\section{The contribution of functional genome-wide pooled sgRNA screens}

The rarity of experimental results derived from animal models or immortalized cell lines has led researchers to conduct observational studies, such as genome-wide association studies (GWAS), in order to identify genes are strongly associated with disease onset. Data from numerous studies [The Cancer Genome Atlas (CGA) (132), the Cancer Cell Line Encyclopedia (CCLE) (133) and the Encyclopedia of DNA Elements (ENCODE) (134)] were previously collected to provide deeper insight into the association of genes with disease predisposition (132-134); however, they were proven to be insufficient. Respectively, genome-wide loss-of-function screens employed RNAi approaches, but they did not prove to be particularly beneficial due to the partial knockdown of predetermined genes, random side-effects and their propagation in protein-coding genes (135). Therefore, despite the accumulation and reliability of the existing results, the researchers were unable to discriminate which genetic variants are implicated in particular disease phenotypes. The recent generation of unbiased genome-wide functional CRISPR screens has identified the functional role of thousands of genomic elements in parallel, irrespective of their position in the coding or noncoding compartment. In addition, CRISPR screens have been used for both the positive and negative selection of genes that are usually implicated in tumorigenesis.

As regards the construction of sgRNA libraries mediated by the CRISPR system, it has been noted that the principles of constructing large scale screens are as follows: i) The use of cloning tools for the pooled synthesis of sgRNAs (135-137); ii) the design of three up to ten sgRNAs that mark a specific gene (135); and iii) the consistency of Cas9 nuclease and its relevant sgRNAs. In brief, libraries are produced as DNA and are incorporated into plasmids via cloning to generate lentiviruses (138). The pool of sgRNAs (represented by oligonucleotides) often targets 104 to 105 different genes and multiple sgRNAs are designed to augment the accuracy at specific target genes. In addition, lentiviruses expressing Cas9 nuclease and sgRNA are delivered at a low multiplicity of infection (MOI), enabling a single sgRNA to be introduced into the cell (138). At the end of the procedure, the lentiviral library of sgRNAs is amenable to phenotypical tests and high-throughput sequencing in order to identify and classify the gene targets that are enriched or diminished in various conditions (139). Despite the advances in designing pooled libraries, certain biases have not been circumvented, such as library synthesis and defaults during experimental procedures, such as cloning.

When it comes to the classification of CR ISPR screens, they can be subdivided into CRISPR nuclease screens (CRISPRn screens), CRISPR interference screens (CRISPRi screens) and CRISPR activation screens (CRISPRa screens). The main differences between the CRISPRn and CRISPRi screens are as follows: In CRISPRn screens, Cas9 nuclease targets any gene surrounded by a PAM sequence, causing its elimination. For example, CRISPRn screens have been used in the identification of significant developmental genes (135), as well as genes implicated in cancer growth (140). However, the results have not been particularly encouraging, due to the restricted number of cells (141) and the phenotypes following inactivation of the anticipated gene, possibly resulting from in-frame insertion/deletions (INDELs) and hypomorphic alleles (142). These pitfalls have led scientists to the revelation that CRISPR screens can be modified to included Cas9 using CRISPR interference (CRISPRi) (143). Thus, CRISPRi screens, which conjugated dCas9 with different transcriptional repression domains, accomplished highly efficient transcriptional silencing $(144,145)$ in any given cell type, including iPSCs (146). In general, the effects mediated by CRISPRi are more efficient, rapid, specific and homogenous as opposed to those caused by Cas 9 nuclease. The only difficulty associated with CRISPRi screens is that dCas9-KRAB inhibits gene expression only when sgRNA is targeted to the transcription start site (TSS) of a gene (145). Overall, the efficacy of CRISPR interference has been shown to be significantly affected by certain parameters, such as the length of sgRNA, the sequence complementarity, the distance of target gene from transcriptional start site (TSS) and the chromatin state constitute the factors that influence the power of CRISPRi. The minimal length of sgRNA for efficient silencing should be 12 nucleotides, whereas the minimum length of PAM should be two nucleotides (143). Theoretically, the genomic 
sequence that can be targeted by Cas 9 for efficient silencing should be $268 \mathrm{Mb}\left(4^{14}\right)$. The specificity is dictated by two PAM nucleotides and 12 nucleotides between the sgRNA and DNA stretch, indicating that the alteration, on average, of one PAM nucleotide is efficient to abolish CRISPR interference (143). Notably, CRISPRi is the most effective when the sgRNAs targeted a region of $150 \mathrm{bp}$ downstream or upstream of the TSS (145).

dCas9, coupled with multiple copies of the activator effector domain, have also been used, thereby accelerating the transcriptional enrichment of the gene of interest and inducing the generation of CRISPRa screens (145). In this manner, CRISPRa screens have the potential to elucidate phenotypes based on the overexpression of certain genes (145), thus offering advantage over the previously used cDNA screens that included elaborate design of cDNAs. An additional advantage of CRISPRa screens over cDNA screens is that they induce transcriptional expression even from secondary transcriptional start sites, particularly if one considers that the design principle of sgRNAs is based on targeting any sequence with a transcriptional start site that is surrounded by a PAM sequence. For example, novel CRISPRa screens have been designed, conjugating dCas9 with distinct transcriptional activators in order to search for gain-of-function phenotypes $(147,148)$. Nonetheless, CRISPRa screens cannot be used to stimulate the expression of highly repressed genes. Another method includes fusing dCas 9 to different domains of epigenetic modifiers, as an attempt to elucidate the effects of epigenetic modifications on chromatin states. Using truncated sgRNAs or building redundancy with several sgRNAs targeting each locus, constitute important design principles for filtering out false positive signals and improving the interpretability of screening data.

sgRNA libraries were first employed for the identification of novel target gene high-confidence biomarkers, thus aiding in the design of innovative therapeutic options. At a genomewide level, CRISPR knock-out libraries were constructed to show sensitivity or resistance to classical therapeutic inhibitors (6-thioguanine and vemurafenib), thus revealing novel drug resistant genes $(135,136)$. For example, deficient libraries (termed Cas9 knockout-GeCKO libraries) were constructed using sgRNAs with the aim of identifying driver genes, whose loss confers resistance to the classical therapy of melanoma, using the BRAF inhibitor, vemurafenib (135). In the same context, a loss of function CRISPR library was generated at the genome-wide level in order to identify genes that were involved in uncontrolled cell growth and pluripotency (135). Following this, the candidate genes were engrafted into mice and generated tumor formation, demonstrating their functional significance in metastasis. In the same context, another CRISPR-mediated screen eliminated candidate genes that were downregulated in Ara-C resistant AML cell lines and highlighted the functional significance of Dck as the primary contributor conferring resistance to the chemotherapeutic Ara-C (149). Tzelepis et al provided convincing evidence regarding the functional sensitivities and potential therapeutic targets in five cell lines that mirrored the transcriptional landscape of AML: MOLM-13, MV4-11, $H L-60, O C I-1 M L 2$ and $O C I-A M L-3$. As a result, the KAT2A molecule (histone lysine acetylatransferase-SAGA member) was identified as a therapeutic target of utmost importance. The therapeutic potency of $K A T 2 A$ was confirmed in an ex vivo leukemia mouse model (Rosa26; Flt3ITD ${ }^{-/+}$with the retroviral infection of MML-AF9 or MLLAF4), further demonstrating its harmless nature in normal hematopoietic cells (150). Respectively, the sensitivity of certain genes to ATR inhibition (151) and p53 expression status (152) on a genome-wide and high-throughput level using CRISPR screens was also demonstrated.

The benefits of CRISPR-based screens are not restricted to the identification of genes that are implicated in drug resistance and tumorigenesis; their use also expands to the study of the genomic alterations that confer resistance to classic therapeutic options. When it comes to elucidating the genomic alterations that cause tumor resistance, researchers have used the CRISPR approach to identify nucleotide alterations (including kinesin-5 A133P mutation or exportin-1 cysteine 528 residue) that confer loss of sensitivity to classic clinical drugs, such as Ispinesib (an inhibitor of kinesin-5) in osteosarcoma therapy (153) and Selinexor (inhibitor of exportin-1) in multiple myeloma (154). Last but not least, Steinhart et al used CRISPR screens in RNF43-mutant pancreatic ductal adenocarcinoma (PDAC) cells, identifying novel therapeutic targets and opening up new avenues for antibody generation (155).

Zhu et al modified CRISPR screens in a manner that paired guide RNAs were used to ablate regions of long noncoding RNAs of 700 bp in length, as the indel mediated by one sgRNA was insufficient to cause loss-of-function phenotype. Using this particular method, 700 lncRNAs in the human genome were screened, taking into consideration that the careful design of guide RNAs is a prerequisite for avoiding overlap with other functional elements (156). Undoubtedly, the optimization of the procedure is essential for the identification of the underlying mechanisms of action of non-coding RNAs, as the modified method could be amenable to other regulatory elements, such as microRNAs. In other words, unbiased genome-wide functional screens can be used to dissect new enhancers and other regulatory elements that have profound impact on the protein level.

Jaitin et al reported a method in which single-cell RNA sequencing (RNA-seq) was combined with CRISPR-pooled screens in an attempt to decipher the regulatory circuits of myeloid development. Specifically, they constructed lentiviral backbones, each of which was composed of a sgRNA expression cassette, transcribed UGI (unique guide index) and the fluorescent selection marker. The concept was based on tracing each sgRNA located in CRISPR-pooled screens, taking into consideration the expression pattern of unique guide index (UGI) and the data acquired by single-cell RNA-seq. The presence of fluorescent marker aided in the selection of cells. In other words, the researchers implemented the method such that they managed to compare fluorescent densities with transcription modules, as represented by UGI read counts, thus highlighting the factors involved in developing the distinct immune subpopulations and delineating the genotype-toassociations in single cells. The results supported that Cebpb was the determinant factor controlling the differentiation of myeloid cells to either dendritic or monocyte cells. In the case of $C e b p b$ deficiency, Irf8 played a vital role in the dendritic cell differentiation route (157). 


\section{The combination of immune and CRISPR system against complex diseases}

Immunotherapy has arisen as a novel method in the treatment of cancer. Tumor-specific T cells can be modulated and infused into the body of patients suffering from synovial cell sarcoma, lymphoma or melanoma or leukemia (158), with significant implications in personalized therapy.

A recent immunotherapy breakthrough was based on the use of CARs, which bind to specific antigens in cancer cells (159). These receptors have attracted much attention as they can be very easily engrafted in any patient, circumventing any possibility of immunogenicity. Evidently, the concept is based on the complete matching of CAR on T cells with the antigen of cancer cells, with the aim of eliminating cancer cells. In the past, genetically edited CAR-T cells produced by ZFNs, TALEN nucleases did not yield the desired results. Nowadays, $T$ cells can be reprogrammed using the CRISPR gene-manipulating system and can be used to eradicate leukemia cells or to treat patients with relapsed B-cell malignancies in remission. For example, Eyquem et al demonstrated that Cas9-modified effector T cells displayed CD19-specific CAR receptor, recognizing the specific sequence of $\mathrm{T}$ cell receptor alpha constant (TRAC) and successfully treating acute lymphoblastic leukemia in a mouse model (160). In this manner, outpaced modified effector-T cells proved to be very efficient in recognizing antigen following repeated exposures, and prevented the expansion of cancer cells as well as exhaustion of T cells. In parallel, certain pharmaceutical companies, including Novartis, have used the CRISPR technology in CAR-T cells in order to decipher the most suitable therapeutic application in each cancer type. Following approval from the Recombinant DNA Advisory Committee at the US National Institutes of Health, clinical trials have been conducted on castration-resistant prostate cancer, muscle-invasive bladder cancer, lung cancer and metastatic renal cell carcinoma, using CRISPR technology (161).

A cornerstone strategy in the field of cancer immunotherapy is the abrogation of 'immune checkpoints', such as PD-1 and CTLA-4. The principle is based on PD-L1 binding expressed by cancer cells at the PD-1 receptor in chronically activated or exhausted $\mathrm{T}$ cells, leading to an exacerbation of cancer cell growth and in turn compromising the anti-tumor immune effect of activated T cells against cancer cells, through engagement of PD-1 receptor to the PDL-1 molecule (162). For this reason, in an attempt to couple the 'immune check-point' and the CRISPR system, researchers have produced RNP complexes composed of sgRNA and Cas9 (Cas9 RNPs), as well as single-stranded DNA oligonucleotides as a template for homology-directed repair to replace the expression of PD-1 in human primary T cells, rendering them more effective (40). The same research team employed Cas9-RNA RNPs to introduce knock-in modifications in the CXCR4 coreceptor of human primary $\mathrm{T}$ cells in the face against HIV infection (40). Undoubtedly, the particular research study became a landmark in $\mathrm{T}$ cell genome engineering, presentinga fast, efficient and very safe method of modulating primary immune cells, as Cas9 RNP complex delivery was reduced to $24 \mathrm{~h}$, with significant implications in the amelioration of side-effects. Cas 9 RNP technology needs to be improved due to the low rate of the resulting modifications (20\%), following the enrichment of FAC-sorted cells with low protein expression. In addition, one should take into consideration that the efficiency of T cell editing can be affected by the dynamics of their chromatin state, their activation potential or other exogenous signals.

Yang et al identified the molecular changes that inhibited BCR-dependent $\mathrm{NF}-\kappa \mathrm{B}$ stimulation in the activated B cell-like (ABC) type of diffuse large B cell lymphoma(DLBCL), using SMAC mimetics. The researchers used the CRISPR system to demonstrate the specificity of SMAC mimetics, particularly in lymphoma subtypes and to show that SMAC mimetics prevent the recruitment of LUBAC ligase or BCL10 to the CBM complex (CARD11-MALT1-BCL10) and the existing redundancy between cIAPs (163).

On the other hand, the CRISPR approach seems to be a beneficial therapeutic tool in cancer types originating from viruses. In particular, it has been shown that the CRISPR system can combat oncolytic viruses by removing viral oncogenes or targeting genes responsible for viral genome maintenance and replication. For example, the CRISPR genome engineering tool has emerged as a great therapeutic option in patients infected with hepatitis B virus (HBV), which has life-threatening consequences, such as cirrhosis and most likely, hepatocellular carcinoma (164). The attack against the HBV virus was demonstrated through the suppression of HBV antigen expression in mice deficient for cccDNA, via the CRISPR system (165). Recently, another application of the CRISPR method against the HBV virus was shown to eliminate the recombinant form of cccDNA that causes viral persistence (166). In the context of hepatic defects caused by infections, nuclease-deficient FnCas 9 has been reported to hinder the synthesis of $\mathrm{HCV}$ protein upon engagement of sgRNAs in the genome (167).

The Epstein-Barr Virus (EBV), which is related to an increased incidence of lymphomas, such as Burkitt lymphoma, Hodgkin's lymphoma, non-Hodgkin's lymphoma, as well as nasopharyngeal carcinoma, constitutes another example of a virus causing severe infections in humans. The modification of Burkitt lymphoma cells mediated by Cas 9 nuclease has resulted in the cessation of viral replication and cell proliferation (168). Notably, the CRISPR system has also been shown to disrupt the HPV virus genes in both 'in vitro' and 'in vivo' xenograft models (169).

\section{The CRISPR system against HIV infection}

Antiretroviral therapy (ART) has thus far been used to eliminate infections caused by HIV, but without the anticipated outcomes. The disadvantages that render ART ineffective include administration for a prolonged period of time, the appearance of transient results in patients and the incidence of several sideeffects. Nonetheless, adoptive T cell therapy has been applied as a therapeutic option against cytomegalovirus (CMV) and EBV $(158,170,171)$. When it comes to therapeutic strategies against human immunodeficiency virus (HIV), three promising therapies have been postulated thus far: i) Remodeling of the immune response through the enhancement of HIV-infected cell awareness and not via the recruitment of a large number of $\mathrm{T}$ cells, so that $\mathrm{T}$ cells can boost the response of other immunological populations; ii) increasing the action and endurance 
of T cells; and iii) triggering the immune system to develop memory cells, since HIV escapes immune mechanisms through viral quasispecies (vQS) or via mutagenesis at specific epitopes (Fig. 5). In principle, the memory $\mathrm{T}$ cell population can be triggered to create viral particles upon interruption of antiviral therapy, in the sense that HIV can be managed through an edited reservoir of memory $\mathrm{T}$ cells.

The remodeling of the immune response can be achieved by three different methods, all of which are aimed at expanding the compartment of HIV-specific T cells. These methodologies also attempt to refine the immune response against HIV by providing either mono-specific $\mathrm{T}$ cells or poly-specific $\mathrm{T}$ cells or modified $\mathrm{T}$ cells. In this context, HIV-directed T cells, activated by cytokines, have been used as a shield against HIV (171). However, mono-specific T cell expansion has proven to be insufficient against HIV, as the virus can circumvent the host immune system. Clinical studies have demonstrated that $\mathrm{CD}^{+} \mathrm{T}$ cells can be directed towards HLA A2 epitopes, thus eliciting responses against gp120, p17, p24 and Nef (172) or CD8 ${ }^{+} \mathrm{T}$ cells specific for Gag, in conditions that included OKT3 and IL-2 (173), without causing any differences in the viral load. At the same time, another clinical study reported no significant changes in the viral load using T cells specific for HIV: Gag p17-8 SLYNTVATL and Pol VIYQYMDDL (174). It was also postulated that the cure of HIV patients was unresolved due to the transient nature and the narrowed efficiency of T cells. Notably, the importance of increasing the persistence and efficacy of the immune response against HIV was highlighted.

An infusion of 'poly-specific $\mathrm{T}$ cells' that recognize different HIV antigens has also been employed to eliminate the HIV virus. Specifically, 'polyclonal HIV-specific T cells were stimulated following exposure to multiple HIV antigens, even upon non-immunodominant epitopes. Additionally, the poly-specific $\mathrm{T}$ cells were concentrated without any requirement of class presentation, contributing to a broader range of therapeutic implementation. In the clinical setting, broadlyspecific cytotoxic T cells (HXTCs) were constructed to exhibit immune reactions with Gag, Nef and Pol epitopes and resulted in eradication of HIV replication (175). The beneficial effect of HXTCs was also validated in HIV-positive individuals with hematological perturbations (176). The results of the clinical trials have been registered (https://clinicaltrials.gov/). The implantation of multi-antigen $\mathrm{T}$ cell clones against HIV is currently being studied in a clinical trial (NCT02208167) (177).

Another promising approach is altering the genetic properties of $\mathrm{T}$ cells, i.e., equipping them with artificial TCRs or CARs that are composed of an extracellular region responsible for recognition of HIV antigens and an activationdomain $(178,179)$. Both types of receptors are modified in such a manner that they bind epitopes, apart from the individual HLA type of each patient, thus enhancing the therapeutic potential of the approach. The distinguishable characteristic of artificial TCRs is their crosstalk with a broad range of epitopes, thus aiding in the design of specific immune responses against certain epitopes and their interaction with crude viral proteins, irrespective of the patient's HLA type. Of note, a clinical study conducted in 2008 which included modified T cells loaded with specific SL9 TCRs, demonstrated the attenuation of HIV levels in immunodeficient mice (NOD/scid/IL-2R $\left.\gamma c^{\text {nul }}\right)(180)$.
It should be noted, however, that the modified $\mathrm{T}$ cells were loaded with TCR receptors recognizing HLA-A*02 restricted P17 epitope SLYNTVATL (A2-SL9), which are related to depletion of HIV in chronic infection (180), thereby helping to overcome the immune escape exhibited by some HIV variants. Respectively, the hallmarks of CARs that distinguish them from TCRs are their ability to provide long-term protection without side-effects and their low immunogenicity. T cells were constructed to include a CAR receptor comprised from a CD4 extracellular domain that recognizes the Env glycoprotein of HIV and the intracellular signaling domain, termed 'CD4zeta-modified T cells'. When such modified T cells were used in a clinical trial (NCT01013415) in distinct phases, they produced very exciting results with regards to specified immunity and persistence of $\mathrm{T}$ cells against HIV, in combination with a reduction of the HIV burden $(181,182)$.

As a second immunological approach, it was observed that $\mathrm{CD}^{+} \mathrm{T}$ cells are recruited at the site of infection, supporting the presence and persistence of cytotoxic T cells against HIV (183). Specifically, the complex assembled between CD4 and MHCII determined the response of $\mathrm{T}$ helper cells to antigen and orchestrated a complete immune response mediated by $\mathrm{T} \mathrm{CD} 8^{+}$cells. In the same context, gene editing strategies have been employed to abolish the entry of HIV in an organism, via eradication of its receptors. For example, it was previously demonstrated that a patient who received a transplant with mutated CCR5 receptor at delta 32 position was cured, acquiring natural HIV resistance (184). Initially, the elimination of HIV coreceptors was achieved using ZNFs that combined Fok1 endonuclease with the DNA-binding zinc finger domain (185). At the preclinical level, ZNFs have been employed for the disruption of HIV coreceptors (CXCR4 or CCR5) (186) at a successful rate, allowing the implementation of ZNF nucleases against HIV in the clinical setting (187). However, the use of ZNFs against HIV infection was hindered by the potential cross-reactivity and side-effects (188). Compared to ZNFs, the CRISPR system was shown to be more beneficial due to its multiplex capacity to disrupt the function of both HIV coreceptors with amenable side-effects (189). In addition, Kaminski et al demonstrated another convincing method through which persistent expression of Cas 9 can impede HIV-1 replication in infected CD4 ${ }^{+}$ $\mathrm{T}$ cells and protect HIV-1-infected T cells against new infection. Specifically, it was shown that the excision of the genomic regions of the HIV-1 promoter that are located at the 5' long terminal repeat (LTR) in 2D10 $\mathrm{CD}^{+} \mathrm{T}$ cells, was responsible for HIV eradication (190).

In an attempt to increase the persistence of $\mathrm{T}$ cells, the latter method employed enrichment of T cells with the memory phenotype so as to combat every new infection more rapidly and efficiently. Apart from the infusion of $\mathrm{T}$ memory cells in the cancer setting (191), the T cell memory reservoir has been employed against HIV in the clinical setting (192). To sum up, $\mathrm{T}$ cell engineering holds great promise in the therapeutic management of HIV in the absence of ART.

\section{Challenges associated with the CRISPR-based gene method and alternative methods}

For the successful implementation of a therapeutic approach based on the CRIPSR method, the existing challenges include 
increasing the specificity of CRISPR system, as well as delivering Cas9 nuclease and its sgRNAs without side-effects. In this session, we analyze proposed methods with which to circumvent these difficulties.

Challenge 1: Delivery. First, the 'ex vivo' delivery of Cas9 nuclease and its sgRNAs has been reported to be achieved with the use of plasmids or classical viral methods (adenovirus, lentivirus, adeno-associated virus or retrovirus). In parallel, Cas9 nuclease has been shown to be delivered through non-viral methods, including cationic lipids or nanoparticle encapsulation or electroporation (193) or microinjection $(194,195)$. In these cases, Cas 9 nuclease and its gRNA are delivered in the form of RNPs, resulting in a long-term response.

In the case of plasmids, the transferred components are inserted into the nuclear area, thus ensuring that delivery is restricted to dividing cells and the danger of insertional mutagenesis usually associated with viruses is eliminated (196). Regarding the 'ex vivo' delivery of the CRISPR system constituents, the iTOP technique and mechanical cell derangement are the current methods. In the case of mechanical cell deformation, membranes are temporally disturbed, following the collection of cell samples in microfluidic devices, allowing the passive diffusion of substances in non-nuclear regions. Single-strand DNA and plasmids have been reported to employ the mechanism of delivery (197). In the iTOP method, macromolecules are delivered into cells via micropinocytosis and using propanebetaine with minimal toxicity (198). In addition, Ha et al have presented an innovative way of delivery through Poly-sgRNA/siRNA nanoparticles, in order to disrupt gene expression (199). The principle in using these nanoparticles is based on the assembly of siRNA (substrate of Dicer) and sgRNAs, which are cleaved through the action of Dicer following rolling circle transcription (RCT). The advantages are as follows: i) Minimal toxicity; ii) nanoparticle strength and stability; and iii) single administration of components to ensure the permanent disarrangement of target gene expression (199). Other delivery methods have been reported to be involved in the 'in vivo' transfer of constituents of the CRISPR system. The first includes the encapsulation of Cas9 nuclease and the appropriate sgRNAs in DNA nanoclews, which constitute DNA nanoparticles constructed by rolling circle amplification (200). DNA nanoclews have been postulated as a suitable choice for delivery as they offer a high intrusion of DNA nanoparticle delivery into cells (200). A different rationale has been suggested that fuses the C-terminal end of Cas9 nuclease with a 'nona-arginine' based cell penetrating peptide (CPP), thereby recruiting the appropriates gRNA (201). In both cases, the positive charge of particles is responsible for the direct entry of the CRISPR system in cells.

Typically, Cas9 nuclease and sgRNA can be delivered either as DNA or RNA, and both can be packaged into viral vectors. The advantage of viral vectors in transferring the CRISPR system is attributed to their ability to regulate gene expression in a spatial-temporal manner, given that a viral vector has the selected promoter to guide transcription of Cas9 and its sgRNA, even though insertional mutagenesis and immunogenic responses can still occur (202). Adenoviruses have been proposed as the safest viral method in transferring the CRISPR components, due to their serotype specificity and low immunogenicity, despite their low packaging capacity. For example, recent data have highlighted the AAV9 vector as the ideal method in transferring the CRISPR components in the Duchenne dystrophin gene $(81,203,204)$. In another study, Gomez et al engineered adeno-associated (AAV) virus exposing phytochrome interacting factor 6 motifs (PIF6), to interact with phytochrome $\mathrm{B}$ (PhyB) factor in response to red light, thus attaining high nuclear translocation of virus in cells and implying a proposal of transferring CRISPR system through adeno-associated virus (205). Further on, Ran et al used an alternative version of Cas9 (SaCas9), which was $1 \mathrm{~kb}$ shorter in length than Cas9 nuclease, and was packaged into the AAV serotype 8 vector. The deficiency of ApoB and PSCK9 was determined to be at a rate of $40 \%$ in hepatocytes (206).

In order to avoid the danger of insertional mutagenesis, cationic lipid nanoparticles (LNPs) have been suggested as an extraordinary non-immunogenic selection for the intracellular delivery of anionic molecules that can be encapsulated $(207,208)$. The LNPs can specifically transfer their load in a cell-dependent manner for a long period, taking advantage of the charge, the hydrophobicity/hydrophilicity of the load and biocompatibility/clearance (207). For example, LNPs have been devised to contain the lipid-like material C12-200 for the successful introduction of modifications in hepatocytes, thus highlighting the CRISPR constructs and the homologydirected repair mechanism. The efficacy of gene repair with this method appears to be higher than that accomplished with the use of viruses (39).

Future efforts should focus on delivering the CRISPR components in cell types other than hepatocytes, including non-dividing cells and stem cells, in an attempt to increase intake of the CRISPR components and to pave the road for new therapeutic interventions. In conjunction with studies on materials science, other delivery methods could be implemented in order to boost the efficiency of the CRISPR system and to circumvent the side-effects induced by the classical means of delivery.

Challenge 2: Methods for enhancing Cas9 nuclease activity. Even though most efforts are currently focused on exploring the molecular mechanisms underlying the fundamental biological processes or on improving the therapeutic outcome of a number of diseases, research teams explore several options for the validation or enhancement of Cas9 nuclease activity. The precision of the CRISPR system can be increased by modifying Cas 9 nuclease.

To validate Cas9 nuclease activity, several sequencing methods, in conjunction with in silico prediction programs, have been extensively used, for the detection of the off-target effects in a genome-wide high sensitive manner. Specifically, the efficacy of Cas 9 has been confirmed by integrasedefective lentiviral vector capture (IDLV) (37,209), linear amplification-mediated PCR (LAM-PCR), high-throughput genome-wide translocation sequencing (HTGTS) (210), genome-wide unbiased identification of DSBs enabled by sequencing (GUIDE-seq) $(211,212)$, next-generation sequencing (BLESS) (213) using in situ adapter ligation and digested genome sequencing (Digenome-seq) (214). The above-mentioned tools have been generated with the notion 


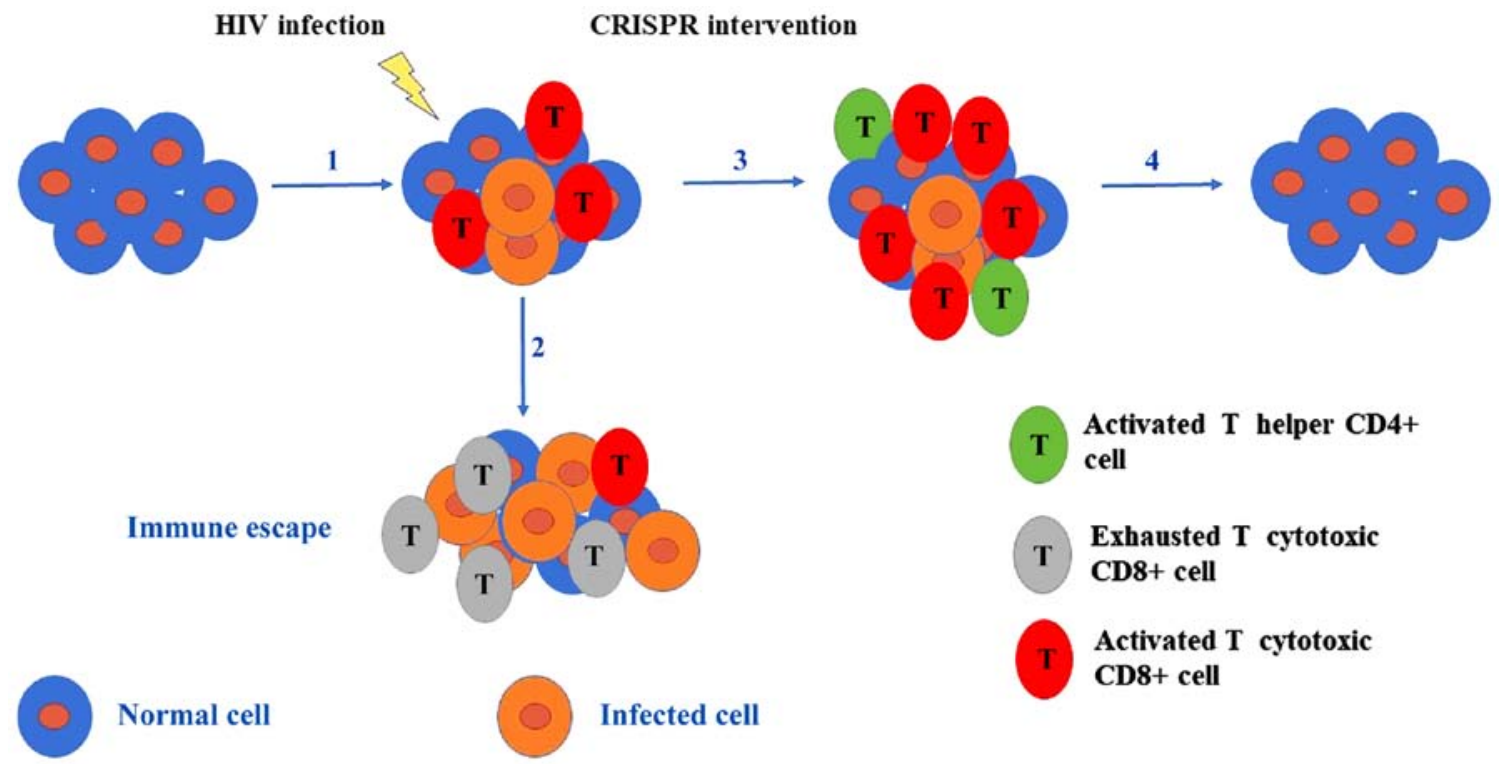

Figure 5. Modified T cell fight against immune HIV variants. In general, T cells recognize and eliminate the HIV-infected cells. However, some cells express variant HIV epitopes that help them to accomplish immune escape. In this context, the CRISPR-edited infected cells can revert to their normal state, recruiting T cells in order to abrogate the HIV challenge. HIV, human immunodeficiency virus; CRISPR, clustered regularly interspaced short palindromic repeats.

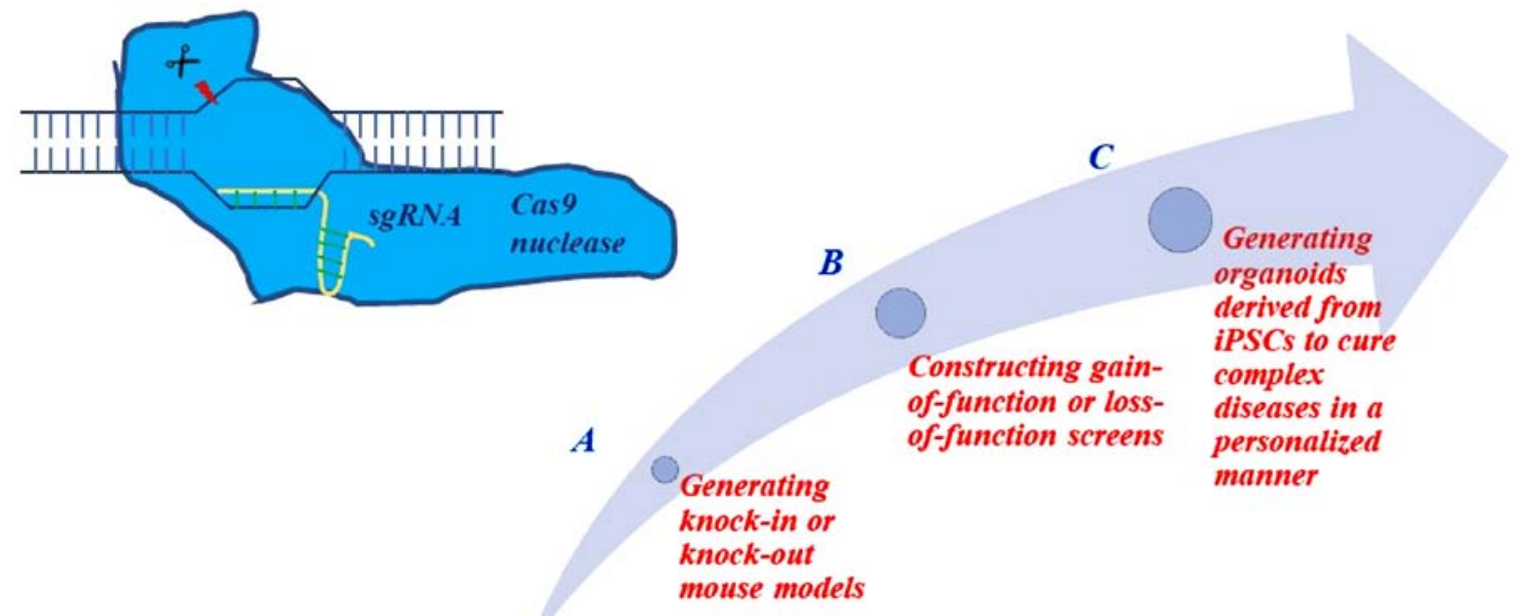

Figure 6. (A) Generation of genetically modified mouse models harboring either eliminations or insertions or chromosome translocations through transfecting Cas9 with single or multiple sgRNAs. (B) Generation of screens using Cas9 and pool of sgRNAs libraries. (C) Targeted mutagenic screens through viral delivery of Cas 9 and targeted sgRNA libraries. Generating organoids to predict the response of patient to administration of potential drugs. sgRNA, single-chimeric guide RNA; Cas9, CRISPR-associated protein 9; iPSCs, induced pluripotent stem cells.

in mind that potential mismatches can be created between sgRNA and complementary DNA sequence. These techniques have enriched our knowledge in bypassing unintended effects mediated by CRISPR system and in determining the implementation of the advanced engineered toolbox. In other words, the challenging nature of the CRISPR system has led to enhancement of Cas9 nuclease precision.

\section{Ways to circumvent the off-target effects of the CRISPR system}

To date, two methods have been reported to eliminate the off-target cleavage effects generated by Cas9 nuclease, either by augmenting the specificity or by decreasing the duration of Cas9 nuclease action.
To enhance the specificity, a first approach is based on truncating the guide RNA from 20 nucleotides to 17 or 18 nucleotides in the genomic region where RNA creates complementary bonds, away from the PAM sequence, while at the same time, Cas9 nuclease retains its activity at desired genomic sequences $(215,216)$. The application of the aforementioned approach has demonstrated the reduction of random effects $(18,37,215,217,218)$. The validity of the method (using truncated sgRNA) has been confirmed by GUIDE-seq or targeted deep sequencing in human cells (216). One potential explanation for the above-mentioned property of the CRISPR system lies on reducing the excess energy that is released by RNA-DNA complementarity, thereby rendering Cas9 nuclease to be very specific on cleavage events. Another method for elevating Cas9 specificity is based on using two 
additional guanine nucleotides in the 5 ' end of the guide sequence $(36,217)$. The underlying mechanism of action remains elusive, but one can envisage that disorganization of the association network between Cas 9 nuclease and the $5^{\prime}$ end of the sgRNA is responsible for reducing the off-target effects mediated by Cas9. In an attempt to boost the Cas9 precision and to minimize the random non-specific cleavage effects, paired Cas9 nickases have been reportedly used. The nickases introduce a single-strand cut (nick) with the same specificity as a regular Cas9 nuclease and a pair of nickases are used to initiate double nicks in each DNA strand, using two separate sgRNAs. The major difference is when two Cas9 nickases are used, long overhangs are produced on each of the cleaved ends, instead of blunt ends. Cas 9 nickase is also distinguishable from Cas9 nuclease because the former has an inactivated catalytic domain (either in RuvC or HNH part) among its six domains: REC I, REC II, Bridge Helix, PAM Interacting, HNH and RuvC (219). Specifically, a D10A replacement at RuvC domain or H840A substitution at HNH takes place, producing a highly specific DNA-binding complex. A characteristic example includes the assembly of one sgRNA with Cas9 nickase, resulting in the reduction of off-target effects in human cells (220). Nevertheless, Cas9 nickase has not been reported as particularly effective in introducing DSBs, as compared to Cas9 nuclease, since Cas9 nickase has been shown to insert point mutations in anticipated target sites $(220,221)$.

Another approach for minimizing side-effects is to use dimerized factors. Dimerized proteins, in particular, use synergistic energy to achieve the desired efficiency. For example, dCas9 was combined with a dimerization-dependent FokI nuclease domain, resulting in a complex named RNA-guided FokI-dCas9 nuclease (RFN) (222). In the same context, RNA-guided FokIdCas9 nuclease (RFN) has been used with truncated sgRNA at the 5 ' end, attaining the best specificity of Cas9 nuclease (223). Finally, it has been shown that Cas9 nuclease precision can be improved by modulating Cas9 with alanine replacements at four residues (25). Of note, the GUIDE-sequencing method (GUIDE-seq) has provided convincing evidence that the Cas9 version containing the alanine substitutions is far more specific than the unmodified Cas9 nuclease (224), preventing non-targeted cleavage events at the DNA sequence.

Hou et al isolated a different form of Cas9 nuclease from Neisseria meningitidis (NmCas9), which exerts its effects very efficiently and with great specificity (225). In-depth analyses have reported that $\mathrm{NmCas} 9$ binds a $24 \mathrm{nt}$ crRNA, providing superior specificity over the previous $20 \mathrm{nt}$ crRNA used by Cas9 derived from Streptococcus pyogenes. Notably, the PAM sequence of NmCas9 comprises an either 5'-NNNNGATT-3' or 5'-NNNNGCTT-3' genomic sequence, through which it accomplishes efficient DNA cleavage. As would be expected, the long PAM sequence employed by NmCas9 confers high specificity. The efficiency offered by $\mathrm{NmCas} 9$ is higher $(60 \%)$ in hESCs and iPSCs compared to that offered by other nucleases and in parallel its use can be expanded to trace cell fate of rare cells (226).

\section{Conclusion}

The rationale based on which the prokaryotic viral defense mechanism is converted to the eminent engineering approach underscores the significance of basic science research. We conclude that the CRISPR system is unique and capable of providing therapeutic applications using stem cells or organoids of different origins. The utility of the CRISPR system seems to be beneficial in the genetic screening for cancer gene validation/discovery. The multilayered characterization of new targets will give comprehensive insights into the therapeutic potential of the particular system, thus guiding its appropriate implementation directly into patients (Fig. 6).

\section{Acknowledgements}

Not applicable.

\section{Funding}

No funding was received.

\section{Availability of data and materials}

Not applicable.

\section{Authors' contributions}

All authors were involved in the conception of the study, and have revised and approved the final manuscript. All authors have taken the responsibility for publishing this review paper. SB performed the literature search, has written the manuscript, has critically analyzed the existing knowledge and has designed the pictures; SB, MA and IC were involved in the acquisition and analysis of 'in vitro' data. MA significantly contributed to editing the manuscript; SB and AMK were involved in the analysis of data in the clinical setting. SB and DAS were involved in analysis of data in the 'HIV setting'. $\mathrm{SB}, \mathrm{MP}$ and VZ were involved in analysis of 'in vivo' data. SB, DAS, MP and VZ were significantly involved in the drafting of the manuscript.

\section{Ethics approval and consent to participate}

Not applicable.

\section{Patient consent for publication}

Not applicable.

\section{Competing interests}

DAS is the Editor-in-Chief for the journal, but had no personal involvement in the reviewing process, or any influence in terms of adjudicating on the final decision, for this article.

\section{References}

1. Bedell VM, Wang Y, Campbell JM, Poshusta TL, Starker CG, Krug RG II, Tan W, Penheiter SG, Ma AC, Leung AY, et al: In vivo genome editing using a high-efficiency TALEN system. Nature 491: 114-118, 2012.

2. Urnov FD, Miller JC, Lee YL, Beausejour CM, Rock JM, Augustus S, Jamieson AC, Porteus MH, Gregory PD and Holmes MC: Highly efficient endogenous human gene correction using designed zinc-finger nucleases. Nature 435: 646-651, 2005. 
3. Kim EJ, Kang KH and Ju JH: CRISPR-Cas9: A promising tool for gene editing on induced pluripotent stem cells. Korean J Intern Med (Korean Assoc Intern Med) 32: 42-61, 2017.

4. Cong L, Ran FA, Cox D, Lin S, Barretto R, Habib N, Hsu PD, Wu X, Jiang W, Marraffini LA, et al: Multiplex genome engineering using CRISPR/Cas systems. Science 339: 819-823, 2013

5. Wu X, Scott DA, Kriz AJ, Chiu AC, Hsu PD, Dadon DB Cheng AW, Trevino AE, Konermann S, Chen S, et al: Genome-wide binding of the CRISPR endonuclease Cas9 in mammalian cells. Nat Biotechnol 32: 670-676, 2014.

6. Doudna JA and Charpentier E: Genome editing. The new frontier of genome engineering with CRISPR-Cas9. Science 346 1258096, 2014

7. Wiedenheft B, Sternberg SH and Doudna JA: RNA-guided genetic silencing systems in bacteria and archaea. Nature 482: 331-338, 2012

8. Mali P, Yang L, Esvelt KM, Aach J, Guell M, DiCarlo JE, Norville JE and Church GM: RNA-guided human genome engineering via Cas9. Science 339: 823-826, 2013.

9. Wright AV, Nuñez JK and Doudna JA: Biology and applications of CRISPR systems: Harnessing nature's toolbox for genome engineering. Cell 164: 29-44, 2016.

10. van der Oost J, Westra ER, Jackson RN and Wiedenheft B Unravelling the structural and mechanistic basis of CRISPR-Cas systems. Nat Rev Microbiol 12: 479-492, 2014

11. Mougiakos I, Bosma EF, de Vos WM, van Kranenburg R and van der Oost J: Next generation prokaryotic engineering: The CRISPR-Cas Toolkit. Trends Biotechnol 34: 575-587, 2016.

12. Bolotin A, Quinquis B, Sorokin A and Ehrlich SD: Clustered regularly interspaced short palindrome repeats (CRISPRs) have spacers of extrachromosomal origin. Microbiology 151: 2551-2561, 2005

13. Westra ER, Semenova E, Datsenko KA, Jackson RN, Wiedenheft B, Severinov K and Brouns SJ: Type I-E CRISPR-cas systems discriminate target from non-target DNA through base pairing-independent PAM recognition. PLoS Genet 9: e1003742, 2013.

14. Jinek M, Chylinski K, Fonfara I, Hauer M, Doudna JA and Charpentier E: A programmable dual-RNA-guided DNA endonuclease in adaptive bacterial immunity. Science 337: 816-821, 2012.

15. Larson MH, Gilbert LA, Wang X, Lim WA, Weissman JS and Qi LS: CRISPR interference (CRISPRi) for sequence-specific control of gene expression. Nat Protoc 8: 2180-2196, 2013.

16. Mojica FJ, Díez-Villaseñor C, García-Martínez J and Almendros C: Short motif sequences determine the targets of the prokaryotic CRISPR defence system. Microbiology 155 733-740, 2009

17. Mei Y, Wang Y, Chen H, Sun ZS and Ju XD: Recent progress in CRISPR/Cas9 technology. J Genet Genomics 43: 63-75, 2016

18. Ran FA, Hsu PD, Wright J, Agarwala V, Scott DA and Zhang F Genome engineering using the CRISPR-Cas9 system. Nat Protoc 8: 2281-2308, 2013.

19. Drost J and Clevers H: Who is in the Driver's Seat: Tracing cancer genes using CRISPR-barcoding. Mol Cell 63: 352-354, 2016

20. Lin S, Staahl BT, Alla RK and Doudna JA: Enhanced homologydirected human genome engineering by controlled timing of CRISPR/Cas9 delivery. eLife 3: e04766, 2014.

21. Ghezraoui H, Piganeau M, Renouf B, Renaud JB, Sallmyr A, Ruis B, Oh S, Tomkinson AE, Hendrickson EA, Giovannangeli C, et al: Chromosomal translocations in human cells are generated by canonical nonhomologous end-joining. Mol Cell 55: 829-842, 2014.

22. Roukos V and Misteli T: The biogenesis of chromosome translocations. Nat Cell Biol 16: 293-300, 2014.

23. Komor AC, Kim YB, Packer MS, Zuris JA and Liu DR: Programmable editing of a target base in genomic DNA without double-stranded DNA cleavage. Nature 533: 420-424, 2016.

24. Suzuki K, Tsunekawa Y, Hernandez-Benitez R, Wu J, Zhu J, Kim EJ, Hatanaka F, Yamamoto M, Araoka T, Li Z, et al In vivo genome editing via CRISPR/Cas9 mediated homologyindependent targeted integration. Nature 540: 144-149, 2016.

25. Nishimasu H, Ran FA, Hsu PD, Konermann S, Shehata SI, Dohmae N, Ishitani R, Zhang F and Nureki O: Crystal structure of Cas9 in complex with guide RNA and target DNA. Cell 156: 935-949, 2014

26. Christian M, Cermak T, Doyle EL, Schmidt C, Zhang F, Hummel A, Bogdanove AJ and Voytas DF: Targeting DNA double-strand breaks with TAL effector nucleases. Genetics 186: 757-761, 2010.
27. Kabadi AM, Ousterout DG, Hilton IB and Gersbach CA: Multiplex CRISPR/Cas9-based genome engineering from a single lentiviral vector. Nucleic Acids Res 42: e147, 2014.

28. Sadikovic B, Al-Romaih K, Squire JA and Zielenska M: Cause and consequences of genetic and epigenetic alterations in human cancer. Curr Genomics 9: 394-408, 2008.

29. Baliou S, Adamaki M, Kyriakopoulos AM, Spandidos DA, Panayiotidis M, Christodoulou I and Zoumpourlis V: Role of the CRISPR system in controlling gene transcription and monitoring cell fate (Review). Mol Med Rep 17: 1421-1427, 2018.

30. Swiech L, Heidenreich M, Banerjee A, Habib N, Li Y, Trombetta J, Sur $\mathrm{M}$ and Zhang F: In vivo interrogation of gene function in the mammalian brain using CRISPR-Cas9. Nat Biotechnol 33: 102-106, 2015.

31. Yang H, Wang H, Shivalila CS, Cheng AW, Shi L and Jaenisch R: One-step generation of mice carrying reporter and conditional alleles by CRISPR/Cas-mediated genome engineering. Cell 154: 1370-1379, 2013

32. Torres R, Martin MC, Garcia A, Cigudosa JC, Ramirez JC and Rodriguez-Perales S: Engineering human tumour-associated chromosomal translocations with the RNA-guided CRISPR-Cas9 system. Nat Commun 5: 3964, 2014.

33. Canver MC, Bauer DE, Dass A, Yien YY, Chung J, Masuda T, Maeda T, Paw BH and Orkin SH: Characterization of genomic deletion efficiency mediated by clustered regularly interspaced short palindromic repeats (CRISPR)/Cas9 nuclease system in mammalian cells. J Biol Chem 292: 2556, 2017.

34. Lupiáñez DG, Kraft K, Heinrich V, Krawitz P, Brancati F, Klopocki E, Horn D, Kayserili H, Opitz JM, Laxova R, et al: Disruptions of topological chromatin domains cause pathogenic rewiring of gene-enhancer interactions. Cell 161: 1012-1025, 2015.

35. Choi PS and Meyerson M: Targeted genomic rearrangements using CRISPR/Cas technology. Nat Commun 5: 3728, 2014.

36. Cho SW, Kim S, Kim Y, Kweon J, Kim HS, Bae S and Kim JS: Analysis of off-target effects of CRISPR/Cas-derived RNA-guided endonucleases and nickases. Genome Res 24: 132-141, 2014.

37. Wang H, Yang H, Shivalila CS, Dawlaty MM, Cheng AW, Zhang $\mathrm{F}$ and Jaenisch R: One-step generation of mice carrying mutations in multiple genes by CRISPR/Cas-mediated genome engineering. Cell 153: 910-918, 2013.

38. Yang L, Guell M, Byrne S, Yang JL, De Los Angeles A, Mali P, Aach J, Kim-Kiselak C, Briggs AW, Rios X, et al: Optimization of scarless human stem cell genome editing. Nucleic Acids Res 41: 9049-9061, 2013.

39. Yin H, Xue W, Chen S, Bogorad RL, Benedetti E, Grompe M, Koteliansky V, Sharp PA, Jacks T and Anderson DG: Genome editing with Cas9 in adult mice corrects a disease mutation and phenotype. Nat Biotechnol 32: 551-553, 2014.

40. Schumann K, Lin S, Boyer E, Simeonov DR, Subramaniam M, Gate RE, Haliburton GE, Ye CJ, Bluestone JA, Doudna JA, et al: Generation of knock-in primary human T cells using Cas9 ribonucleoproteins. Proc Natl Acad Sci USA 112: 10437-10442, 2015.

41. Renaud JB, Boix C, Charpentier M, De Cian A, Cochennec J, Duvernois-Berthet E, Perrouault L, Tesson L, Edouard J, Thinard R, et al: Improved genome editing efficiency and flexibility using modified oligonucleotides with TALEN and CRISPR-Cas9 nucleases. Cell Rep 14: 2263-2272, 2016.

42. Platt RJ, Chen S, Zhou Y, Yim MJ, Swiech L, Kempton HR, Dahlman JE, Parnas O, Eisenhaure TM, Jovanovic M, et al: CRISPR-Cas9 knockin mice for genome editing and cancer modeling. Cell 159: 440-455, 2014.

43. Kaulich M, Lee YJ, Lönn P, Springer AD, Meade BR and Dowdy SF: Efficient CRISPR-rAAV engineering of endogenous genes to study protein function by allele-specific RNAi. Nucleic Acids Res 43: e45, 2015.

44. Li Y, Park AI, Mou H, Colpan C, Bizhanova A, Akama-Garren E, Joshi N, Hendrickson EA, Feldser D, Yin H, et al: A versatile reporter system for CRISPR-mediated chromosomal rearrangements. Genome Biol 16: 111, 2015.

45. Xiao A, Wang Z, Hu Y, Wu Y, Luo Z, Yang Z, Zu Y, Li W, Huang $\mathrm{P}$, Tong $\mathrm{X}$, et al: Chromosomal deletions and inversions mediated by TALENs and CRISPR/Cas in zebrafish. Nucleic Acids Res 41: e141, 2013.

46. Heyer J, Kwong LN, Lowe SW and Chin L: Non-germline genetically engineered mouse models for translational cancer research. Nat Rev Cancer 10: 470-480, 2010.

47. Xue W, Chen S, Yin H, Tammela T, Papagiannakopoulos T, Joshi NS, Cai W, Yang G, Bronson R, Crowley DG, et al: CRISPR-mediated direct mutation of cancer genes in the mouse liver. Nature 514: 380-384, 2014 
48. Zuckermann M, Hovestadt V, Knobbe-Thomsen CB, Zapatka M, Northcott PA, Schramm K, Belic J, Jones DT, Tschida B, Moriarity B, et al: Somatic CRISPR/Cas9-mediated tumour suppressor disruption enables versatile brain tumour modelling. Nat Commun 6: 7391, 2015.

49. Doerks T, Copley RR, Schultz J, Ponting CP and Bork P: Systematic identification of novel protein domain families associated with nuclear functions. Genome Res 12: 47-56, 2002.

50. Guerra C, Mijimolle N, Dhawahir A, Dubus P, Barradas M, Serrano M, Campuzano V and Barbacid M: Tumor induction by an endogenous K-ras oncogene is highly dependent on cellular context. Cancer Cell 4: 111-120, 2003.

51. Findlay GM, Boyle EA, Hause RJ, Klein JC and Shendure J: Saturation editing of genomic regions by multiplex homologydirected repair. Nature 513: 120-123, 2014.

52. Hacisuleyman E, Goff LA, Trapnell C, Williams A, Henao-Mejia J, Sun L, McClanahan P, Hendrickson DG Sauvageau M, Kelley DR, et al: Topological organization of multichromosomal regions by the long intergenic noncoding RNA Firre. Nat Struct Mol Biol 21: 198-206, 2014

53. Krishnaswamy JK, Singh A, Gowthaman U, Wu R, Gorrepati P, Sales Nascimento M, Gallman A,Liu D, Rhebergen AM, Calabro S, et al: Coincidental loss of DOCK8 function in NLRP10-deficient and $\mathrm{C} 3 \mathrm{H} / \mathrm{HeJ}$ mice results in defective dendritic cell migration. Proc Natl Acad Sci USA 112: 3056-3061, 2015.

54. Billon P, Bryant EE, Joseph SA, Nambiar TS, Hayward SB, Rothstein $\mathrm{R}$ and Ciccia A: CRISPR-mediated base editing enables efficient disruption of eukaryotic genes through induction of STOP codons. Moll Cell 67: 1068-79.e4, 2017.

55. Blasco RB, Karaca E, Ambrogio C, Cheong TC, Karayol E, Minero VG, Voena $\mathrm{C}$ and Chiarle R: Simple and rapid in vivo generation of chromosomal rearrangements using CRISPR/Cas9 technology. Cell Rep 9: 1219-1227, 2014.

56. Maddalo D, Manchado E, Concepcion CP, Bonetti C, Vidigal JA, Han YC, Ogrodowski P, Crippa A, Rekhtman N, de Stanchina E, et al: In vivo engineering of oncogenic chromosomal rearrangements with the CRISPR/Cas9 system. Nature 516: 423-427, 2014.

57. Nishio M, Kim DW, Wu YL, Nakagawa K, Solomon BJ, Shaw AT, Hashigaki S, Ohki E, Usari T, Paolini J, et al: Crizotinib versus chemotherapy in Asian patients with advanced ALK-positive non-small cell lung cancer. Cancer Res Treat: Jul 6, 2017 (Epub ahead of print). doi: 10.4143/crt.2017.280.

58. Ding Q, Strong A, Patel KM, Ng SL, Gosis BS, Regan SN, Cowan CA, Rader DJ and Musunuru K: Permanent alteration of PCSK9 with in vivo CRISPR-Cas9 genome editing. Circ Res 115: 488-492, 2014

59. Yang DG, Chung YC, Lai YK, Lai CW, Liu HJ and Hu YC: Corrigendum to "Avian Influenza Virus Hemagglutinin Display on Baculovirus Envelope: Cytoplasmic Domain Affects Virus Properties and Vaccine Potential'. Mol Ther 15: 1736, 2007.

60. Cancer Genome Atlas N; Cancer Genome Atlas Network: Comprehensive molecular characterization of human colon and rectal cancer. Nature 487: 330-337, 2012.

61. Sánchez-Rivera FJ,Papagiannakopoulos T, Romero R, Tammela T, Bauer MR, Bhutkar A, Joshi NS, Subbaraj L, Bronson RT, Xue W, et al: Rapid modelling of cooperating genetic events in cancer through somatic genome editing. Nature 516: 428-431, 2014.

62. Chiou SH, Winters IP, Wang J, Naranjo S, Dudgeon C, Tamburini FB, Brady JJ, Yang D, Grüner BM, Chuang CH, et al: Pancreatic cancer modeling using retrograde viral vector delivery and in vivo CRISPR/Cas9-mediated somatic genome editing. Genes Dev 29: 1576-1585, 2015.

63. Annunziato S, Kas SM,Nethe M, Yücel H,Del Bravo J,Pritchard C, Bin Ali R, van Gerwen B, Siteur B, Drenth AP, et al: Modeling invasive lobular breast carcinoma by CRISPR/Cas9-mediated somatic genome editing of the mammary gland. Genes Dev 30: 1470-1480, 2016.

64. Oh B, Hwang S, McLaughlin J, Solter D and Knowles BB: Timely translation during the mouse oocyte-to-embryo transition. Development 127: 3795-3803, 2000.

65. Flemr M and Bühler M: Single-step generation of conditional knockout mouse embryonic stem cells. Cell Rep 12: 709-716, 2015.

66. Malina A, Mills JR, Cencic R, Yan Y, Fraser J, Schippers LM, Paquet M, Dostie J and Pelletier J: Repurposing CRISPR/Cas9 for in situ functional assays. Genes Dev 27: 2602-2614, 2013.

67. Heckl D, Kowalczyk MS, Yudovich D, Belizaire R, Puram RV, McConkey ME, Thielke A, Aster JC, Regev A and Ebert BL: Generation of mouse models of myeloid malignancy with combinatorial genetic lesions using CRISPR-Cas9 genome editing. Nat Biotechnol 32: 941-946, 2014.
68. Chen C, Liu Y, Rappaport AR, Kitzing T, Schultz N, Zhao Z, Shroff AS, Dickins RA, Vakoc CR, Bradner JE, et al: MLL3 is a haploinsufficient 7q tumor suppressor in acute myeloid leukemia. Cancer Cell 25: 652-665, 2014

69. Zhong C, Yin Q, Xie Z, Bai M, Dong R, Tang W, Xing YH, Zhang H, Yang S, Chen LL, et al: CRISPR-Cas9-mediated genetic screening in mice with haploid embryonic stem cells carrying a Guide RNA Library. Cell Stem Cell 17: 221-232, 2015.

70. Park CY, Kim DH, Son JS, Sung JJ, Lee J, Bae S, Kim JH, Kim DW and Kim JS: Functional correction of large factor VIII gene chromosomal inversions in hemophilia a patient-derived iPSCs using CRISPR-Cas9. Cell Stem Cell 17: 213-220, 2015.

71. Huang L, Holtzinger A, Jagan I, BeGora M, Lohse I, Ngai N, Nostro C, Wang R, Muthuswamy LB, Crawford HC, et al: Ductal pancreatic cancer modeling and drug screening using human pluripotent stem cell- and patient-derived tumor organoids. Nat Med 21: 1364-1371, 2015

72. Wang J, Exline CM, DeClercq JJ, Llewellyn GN, Hayward SB, Li PW, Shivak DA, Surosky RT, Gregory PD, Holmes MC, et al: Homology-driven genome editing in hematopoietic stem and progenitor cells using ZFN mRNA and AAV6 donors. Nat Biotechnol 33: 1256-1263, 2015.

73. Hoban MD, Cost GJ, Mendel MC, Romero Z, Kaufman ML, Joglekar AV, Ho M, Lumaquin D, Gray D, Lill GR, et al: Correction of the sickle cell disease mutation in human hematopoietic stem/progenitor cells. Blood 125: 2597-2604, 2015.

74. Xie F, Ye L, Chang JC, Beyer AI, Wang J, Muench MO and Kan YW: Seamless gene correction of $\beta$-thalassemia mutations in patient-specific iPSCs using CRISPR/Cas9 and piggyBac. Genome Res 24: 1526-1533, 2014.

75. Roberts SA, Dong B, Firrman JA, Moore AR, Sang N and Xiao W: Engineering factor Viii for hemophilia gene therapy. J Genet Syndr Gene Ther 1: 1, 2011.

76. Stanek LM, Sardi SP, Mastis B, Richards AR, Treleaven CM, Taksir T, Misra K, Cheng SH and Shihabuddin LS: Silencing mutant huntingtin by adeno-associated virus-mediated RNA interference ameliorates disease manifestations in the YAC128 mouse model of Huntington's disease. Hum Gene Ther 25: 461-474, 2014.

77. Shin JW, Kim KH, Chao MJ, Atwal RS, Gillis T, MacDonald ME, Gusella JF and Lee JM: Permanent inactivation of Huntington's disease mutation by personalized allele-specific CRISPR/Cas9. Hum Mol Genet 25: 4566-4576, 2016.

78. Monteys AM, Ebanks SA, Keiser MS and Davidson BL: CRISPR/ Cas9 editing of the mutant huntingtin allele in vitro and in vivo. Mol Ther 25: 12-23, 2017

79. Xu X, Tay Y, Sim B, Yoon SI, Huang Y, Ooi J, Utami KH, Ziaei A, $\mathrm{Ng} \mathrm{B}$, Radulescu C, et al: Reversal of Phenotypic Abnormalities by CRISPR/Cas9-Mediated Gene Correction in Huntington Disease Patient-Derived Induced Pluripotent Stem Cells. Stem Cell Reports 8: 619-633, 2017.

80. Chung CY, Khurana V, Auluck PK, Tardiff DF, Mazzulli JR, Soldner F, Baru V, Lou Y, Freyzon Y, Cho S, et al: Identification and rescue of $\alpha$-synuclein toxicity in Parkinson patient-derived neurons. Science 342: 983-987, 2013.

81. Long C, McAnally JR, Shelton JM, Mireault AA, Bassel-Duby R and Olson EN: Prevention of muscular dystrophy in mice by CRISPR/Cas9-mediated editing of germline DNA. Science 345: 1184-1188, 2014

82. Schwank G, Koo BK, Sasselli V, Dekkers JF, Heo I, Demircan T, Sasaki N, Boymans S, Cuppen E, van der Ent CK, et al: Functional repair of CFTR by CRISPR/Cas9 in intestinal stem cell organoids of cystic fibrosis patients. Cell Stem Cell 13: 653-658, 2013

83. Firth AL, Menon T, Parker GS, Qualls SJ, Lewis BM, Ke E, Dargitz CT, Wright R, Khanna A, Gage FH, et al: Functional gene correction for cystic fibrosis in lung epithelial cells generated from patient iPSCs. Cell Rep 12: 1385-1390, 2015.

84. Wu Y, Liang D, Wang Y, Bai M, Tang W, Bao S, Yan Z, Li D and $\mathrm{Li} \mathrm{J}$ : Correction of a genetic disease in mouse via use of CRISPR-Cas9. Cell Stem Cell 13: 659-662, 2013.

85. Wu Y, Zhou H, Fan X, Zhang Y, Zhang M, Wang Y, Xie Z, Bai M, Yin Q, Liang D, et al: Correction of a genetic disease by CRISPR-Cas9-mediated gene editing in mouse spermatogonial stem cells. Cell Res 25: 67-79, 2015.

86. Xie N, Gong H, Suhl JA, Chopra P, Wang T and Warren ST: Reactivation of FMR1 by CRISPR/Cas9-mediated deletion of the expanded CGG-repeat of the Fragile X chromosome. PLoS One 11: e0165499, 2016 
87. Horii T, Tamura D, Morita S, Kimura M and Hatada I: Generation of an ICF syndrome model by efficient genome editing of human induced pluripotent stem cells using the CRISPR system. Int J Mol Sci 14: 19774-19781, 2013.

88. Chang CW, Lai YS, Westin E, Khodadadi-Jamayran A, Pawlik KM, Lamb LS Jr, Goldman FD and Townes TM Modeling human severe combined immunodeficiency and correction by CRISPR/Cas9-enhanced gene targeting. Cell Rep 12: 1668-1677, 2015

89. Flynn R, Grundmann A, Renz P, Hanseler W, James WS Cowley SA and Moore MD: CRISPR-mediated genotypic and phenotypic correction of a chronic granulomatous disease mutation in human iPS cells. Exp Hematol 43: 838-848.e3, 2015

90. Osborn MJ, Belanto JJ, Tolar J and Voytas DF: Gene editing and its application for hematological diseases. Int J Hematol 104: $18-28,2016$.

91. Shinkuma S, Guo Z and Christiano AM: Site-specific genome editing for correction of induced pluripotent stem cells derived from dominant dystrophic epidermolysis bullosa. Proc Nat Acad Sci USA 113: 5676-5681, 2016.

92. Bassuk AG, Zheng A, Li Y, Tsang SH and Mahajan VB: Precision Medicine: Genetic Repair of Retinitis Pigmentosa in Patient-Derived Stem Cells. Sci Rep 6: 19969, 2016.

93. Ruan GX, Barry E, Yu D, Lukason M, Cheng SH and Scaria A CRISPR/Cas9-mediated genome editing as a therapeutic approach for leber congenital amaurosis 10. Mol Ther 25: 331-341, 2017

94. Mandegar MA, Huebsch N, Frolov EB, Shin E, Truong A, Olvera MP, Chan AH, Miyaoka Y, Holmes K, Spencer CI, et al CRISPR Interference Efficiently Induces Specific and Reversible Gene Silencing in Human iPSCs. Cell Stem Cell 18: 541-553, 2016.

95. Couzin-Frankel J: Breakthrough of the year 2013. Cancer immunotherapy. Science 342: 1432-1433, 2013.

96. Guye P,Ebrahimkhani MR, Kipniss N, Velazquez JJ,SchoenfeldE, Kiani S, Griffith LG and Weiss R: Genetically engineering selforganization of human pluripotent stem cells into a liver bud-like tissue using Gata6. Nat Commun 7: 10243, 2016.

97. Sharma SV, Haber DA and Settleman J: Cell line-based platforms to evaluate the therapeutic efficacy of candidate anticancer agents. Nat Rev Cancer 10: 241-253, 2010.

98. Lutsenko S: Introduction to the minireview series on modern technologies for in-cell biochemistry. J Biol Chem 291: 3757-3758, 2016.

99. Sato T, Vries RG, Snippert HJ, van de Wetering M, Barker N, Stange DE, van Es JH, Abo A, Kujala P, Peters PJ, et al: Single Lgr5 stem cells build crypt-villus structures in vitro without a mesenchymal niche. Nature 459: 262-265, 2009.

100. Clevers H: Modeling development and disease with organoids. Cell 165: 1586-1597, 2016.

101.Lancaster MA and Knoblich JA: Generation of cerebral organoids from human pluripotent stem cells. Nat Protoc 9 2329-2340, 2014

102. Sayin VI and Papagiannakopoulos T: Application of CRISPRmediated genome engineering in cancer research. Cancer Lett 387: 10-17, 2017.

103. Boj SF, Hwang CI, Baker LA, Chio II, Engle DD, Corbo V, Jager M, Ponz-Sarvise M, Tiriac H, Spector MS, et al: Organoid models of human and mouse ductal pancreatic cancer. Cell 160: 324-338, 2015.

104. Nantasanti S, Spee B, Kruitwagen HS, Chen C, Geijsen N, Oosterhoff LA, van Wolferen ME, Pelaez N, Fieten H, Wubbolts RW, et al: Disease modeling and gene therapy of copper storage disease in canine hepatic organoids. Stem Cell Rep 5: 895-907, 2015 .

105. Walsh AJ, Cook RS, Sanders ME, Arteaga CL and Skala MC: Drug response in organoids generated from frozen primary tumor tissues. Sci Rep 6: 18889, 2016.

106. van de Wetering M, Francies HE, Francis JM, Bounova G, Iorio F, Pronk A, van Houdt W, van Gorp J, Taylor-Weiner A, Kester L, et al: Prospective derivation of a living organoid biobank of colorectal cancer patients. Cell 161: 933-945, 2015.

107. Huch M, Gehart H, van Boxtel R, Hamer K, Blokzijl F, Verstegen MM, Ellis E, van Wenum M, Fuchs SA, de Ligt J, et al: Long-term culture of genome-stable bipotent stem cells from adult human liver. Cell 160: 299-312, 2015.

108. Barker N, Huch M, Kujala P, van de Wetering M, Snippert HJ, van Es JH, Sato T, Stange DE, Begthel $\mathrm{H}$, van den Born M, et al: Lgr5(+ve) stem cells drive self-renewal in the stomach and build long-lived gastric units in vitro. Cell Stem Cell 6: 25-36, 2010.
109. Huch M, Bonfanti P, Boj SF, Sato T, Loomans CJ, van de Wetering M, Sojoodi M, Li VS, Schuijers J, Gracanin A, et al: Unlimited in vitro expansion of adult bi-potent pancreas progenitors through the Lgr5/R-spondin axis. EMBO J 32: 2708-2721, 2013.

110. Huch M, Dorrell C, Boj SF, van Es JH, Li VS, van de Wetering M, Sato T, Hamer K, Sasaki N, Finegold MJ, et al: In vitro expansion of single $\mathrm{Lgr}^{+}$liver stem cells induced by Wnt-driven regeneration. Nature 494: 247-250, 2013.

111. Gao D, Vela I, Sboner A, Iaquinta PJ, Karthaus WR, Gopalan A, Dowling C, Wanjala JN, Undvall EA, Arora VK, et al: Organoid cultures derived from patients with advanced prostate cancer. Cell 159: 176-187, 2014.

112. Karthaus WR, Iaquinta PJ, Drost J, Gracanin A, van Boxtel R, Wongvipat J, Dowling CM, Gao D, Begthel H, Sachs N, et al: Identification of multipotent luminal progenitor cells in human prostate organoid cultures. Cell 159: 163-175, 2014.

113. Heo I and Clevers H: Expanding intestinal stem cells in culture. Cell Res 25: 995-996, 2015.

114. Cooks T, Pateras IS, Tarcic O, Solomon H, Schetter AJ, Wilder S, Lozano G, Pikarsky E, Forshew T, Rosenfeld N, et al: Mutant p53 prolongs NF- $\kappa \mathrm{B}$ activation and promotes chronic inflammation and inflammation-associated colorectal cancer. Cancer Cell 23: 634-646, 2013.

115. Kazanjian A and Shroyer NF: NOTCH signaling and ATOH1 in colorectal cancers. Curr Colorectal Cancer Rep 7: 121-127, 2011

116. Fujii M, Shimokawa M, Date S, Takano A, Matano M, Nanki K, Ohta Y, Toshimitsu K, Nakazato Y, Kawasaki K, et al: A colorectal tumor organoid library demonstrates progressive loss of niche factor requirements during tumorigenesis. Cell Stem Cell 18: 827-838, 2016

117. Drost J, van Jaarsveld RH, Ponsioen B,Zimberlin C, van Boxtel R, Buijs A, Sachs N, Overmeer RM, Offerhaus GJ, Begthel H, et al: Sequential cancer mutations in cultured human intestinal stem cells. Nature 521: 43-47, 2015.

118. Bargou R, Leo E, Zugmaier G, Klinger M, Goebeler M, Knop S, Noppeney R, Viardot A, Hess G, Schuler M, et al: Tumor regression in cancer patients by very low doses of a T cell-engaging antibody. Science 321: 974-977, 2008.

119. Chames P and Baty D: Bispecific antibodies for cancer therapy: The light at the end of the tunnel? MAbs 1: 539-547, 2009.

120. Stagg J, Lejeune L, Paquin A and Galipeau J: Marrow stromal cells for interleukin-2 delivery in cancer immunotherapy. Hum Gene Ther 15: 597-608, 2004.

121. Compte M, Nuñez-Prado N, Sanz L and Alvarez-Vallina L: Immunotherapeutic organoids: A new approach to cancer treatment. Biomatter 3: e23897, 2013.

122. Fuller MK, Faulk DM, Sundaram N, Shroyer NF, Henning SJ and Helmrath MA: Intestinal crypts reproducibly expand in culture. J Surg Res 178: 48-54, 2012.

123. Grün D, Lyubimova A, Kester L, Wiebrands K, Basak O, Sasaki N, Clevers $\mathrm{H}$ and van Oudenaarden A: Single-cell messenger RNA sequencing reveals rare intestinal cell types. Nature 525: 251-255, 2015.

124. Onuma K, Ochiai M, Orihashi K, Takahashi M, Imai T, Nakagama $\mathrm{H}$ and Hippo Y: Genetic reconstitution of tumorigenesis in primary intestinal cells. Proc Natl Acad Sci USA 110: 11127-11132, 2013.

125. Vazin T and Schaffer DV: Engineering strategies to emulate the stem cell niche. Trends Biotechnol 28: 117-124, 2010

126. Lancaster MA, Renner M, Martin CA, Wenzel D, Bicknell LS, Hurles ME, Homfray T, Penninger JM, Jackson AP and Knoblich JA: Cerebral organoids model human brain development and microcephaly. Nature 501: 373-379, 2013

127. Murphy SV and Atala A: 3D bioprinting of tissues and organs. Nat Biotechnol 32: 773-785, 2014.

128. Lindemans CA, Calafiore M, Mertelsmann AM, O'Connor MH, Dudakov JA, Jenq RR, Velardi E, Young LF, Smith OM, Lawrence G, et al: Interleukin-22 promotes intestinal-stem-cellmediated epithelial regeneration. Nature 528: 560-564, 2015.

129. Wilson SS, Tocchi A, Holly MK, Parks WC and Smith JG: A small intestinal organoid model of non-invasive enteric pathogen-epithelial cell interactions. Mucosal Immunol 8: $352-361,2015$

130. Wu K, House L, Liu W and Cho WC: Personalized targeted therapy for lung cancer. Int J Mol Sci 13: 11471-11496, 2012.

131. Tang H and Shrager JB: CRISPR/Cas-mediated genome editing to treat EGFR-mutant lung cancer: A personalized molecular surgical therapy. EMBO Mol Med 8: 83-85, 2016. 
132. Cancer Genome Atlas Research Network. Electronic address edsc, Cancer Genome Atlas Research N. Comprehensive and Integrated Genomic Characterization of Adult Soft Tissue Sarcomas. Cell 171: 950-65.e28, 2017.

133. Barretina J, Caponigro G, Stransky N, Venkatesan K, Margolin AA, Kim S, Wilson CJ, Lehár J, Kryukov GV, Sonkin D, et al: The cancer cell line encyclopedia enables predictive modelling of anticancer drug sensitivity. Nature 483 : 603-607, 2012

134. Consortium EP; ENCODE Project Consortium: An integrated encyclopedia of DNA elements in the human genome. Nature 489: 57-74, 2012.

135. Shalem O, Sanjana NE, Hartenian E, Shi X, Scott DA, Mikkelson T, Heckl D, Ebert BL, Root DE, Doench JG, et al: Genome-scale CRISPR-Cas9 knockout screening in human cells. Science 343: 84-87, 2014.

136. Wang T, Wei JJ, Sabatini DM and Lander ES: Genetic screens in human cells using the CRISPR-Cas9 system. Science 343: 80-84, 2014

137. Koike-Yusa H, Li Y, Tan EP, Velasco-Herrera MC and Yusa K Genome-wide recessive genetic screening in mammalian cells with a lentiviral CRISPR-guide RNA library. Nat Biotechnol 32: 267-273, 2014

138. Sanjana NE: Genome-scale CRISPR pooled screens. Anal Biochem 532: 95-99, 2017

139. Fellmann C, Gowen BG, Lin PC, Doudna JA and Corn JE: Cornerstones of CRISPR-Cas in drug discovery and therapy. Nat Rev Drug Discov 16: 89-100, 2017.

140. Wang T, Birsoy K, Hughes NW, Krupczak KM, Post Y, Wei JJ Lander ES and Sabatini DM: Identification and characterization of essential genes in the human genome. Science 350: 1096-1101, 2015.

141.González F, Zhu Z, Shi ZD, Lelli K, Verma N, Li QV and Huangfu D: An iCRISPR platform for rapid, multiplexable, and inducible genome editing in human pluripotent stem cells. Cell Stem Cell 15: 215-226, 2014.

142. Shi J, Wang E, Milazzo JP, Wang Z, Kinney JB and Vakoc CR Discovery of cancer drug targets by CRISPR-Cas9 screening of protein domains. Nat Biotechnol 33: 661-667, 2015.

143. Qi LS, Larson MH, Gilbert LA, Doudna JA, Weissman JS, Arkin AP and Lim WA: Repurposing CRISPR as an RNA-guided platform for sequence-specific control of gene expression. Cell 152: 1173-1183, 2013.

144. Gilbert LA, Larson MH, Morsut L, Liu Z, Brar GA, Torres SE, Stern-Ginossar N, Brandman O, Whitehead EH, Doudna JA, et al: CRISPR-mediated modular RNA-guided regulation of transcription in eukaryotes. Cell 154: 442-451, 2013.

145. Gilbert LA, Horlbeck MA, Adamson B, Villalta JE, Chen Y, Whitehead EH, Guimaraes C, Panning B, Ploegh HL, Bassik MC, et al: Genome-Scale CRISPR-Mediated Control of Gene Repression and Activation. Cell 159: 647-661, 2014.

146. Takahashi K, Tanabe K, Ohnuki M, Narita M, Ichisaka T, Tomoda $\mathrm{K}$ and Yamanaka S: Induction of pluripotent stem cells from adult human fibroblasts by defined factors. Cell 131: 861-872, 2007.

147. Konermann S, Brigham MD, Trevino AE, Joung J, Abudayyeh OO, Barcena C, Hsu PD, Habib N, Gootenberg JS, Nishimasu $\mathrm{H}$, et al: Genome-scale transcriptional activation by an engineered CRISPR-Cas9 complex. Nature 517: 583-588, 2015 .

148. Cheng AW, Wang H, Yang H, Shi L, Katz Y, Theunissen TW, Rangarajan S, Shivalila CS, Dadon DB and Jaenisch R: Multiplexed activation of endogenous genes by CRISPR-on, an RNA-guided transcriptional activator system. Cell Res 23: 1163-1171, 2013.

149. Rathe SK, Moriarity BS, Stoltenberg CB, Kurata M, Aumann NK, Rahrmann EP, Bailey NJ, Melrose EG, Beckmann DA, Liska CR, et al: Using RNA-seq and targeted nucleases to identify mechanisms of drug resistance in acute myeloid leukemia. Sci Rep 4: 6048,2014

150. Tzelepis K, Koike-Yusa H, De Braekeleer E, Li Y,Metzakopian E, Dovey OM, Mupo A, Grinkevich V, Li M, Mazan M, et al: A CRISPR Dropout Screen Identifies Genetic Vulnerabilities and Therapeutic Targets in Acute Myeloid Leukemia. Cell Rep 17: 1193-1205, 2016.

151.Ruiz S, Mayor-Ruiz C, Lafarga V, Murga M, Vega-Sendino M, Ortega S and Fernandez-Capetillo O: A Genome-wide CRISPR Screen Identifies CDC25A as a Determinant of Sensitivity to ATR Inhibitors. Mol Cell 62: 307-313, 2016.
152. Wanzel M, Vischedyk JB, Gittler MP, Gremke N, Seiz JR, Hefter M, Noack M, Savai R, Mernberger M, Charles JP, et al: CRISPR-Cas9-based target validation for p53-reactivating model compounds. Nat Chem Biol 12: 22-28, 2016.

153. Rath O and Kozielski F: Kinesins and cancer. Nat Rev Cancer 12: 527-539, 2012.

154. Chen C, Siegel D, Gutierrez M, Jacoby M, Hofmeister CC. Safety and efficacy of selinexor in relapsed or refractory multiple myeloma and Waldenstrom macroglobulinemia. Blood 131: $855-863,2018$

155. Steinhart Z, Pavlovic Z, Chandrashekhar M, Hart T, Wang X, Zhang X, Robitaille M, Brown KR, Jaksani S, Overmeer R, et al: Genome-wide CRISPR screens reveal a Wnt-FZD5 signaling circuit as a druggable vulnerability of RNF43-mutant pancreatic tumors. Nat Med 23: 60-68, 2017.

156.Zhu S, Li W, Liu J, Chen CH, Liao Q, Xu P, Xu H, Xiao T, Cao Z, Peng J, et al: Genome-scale deletion screening of human long non-coding RNAs using a paired-guide RNA CRISPR-Cas9 library. Nat Biotechnol 34: 1279-1286, 2016.

157. Jaitin DA, Weiner A, Yofe I, Lara-Astiaso D, Keren-Shaul H, David E, Salame TM, Tanay A, van Oudenaarden A and Amit I: Dissecting immune circuits by linking CRISPR-pooled screens with single-cell RNA-Seq. Cell 167: 1883-1896.e15, 2016.

158. Hinrichs CS and Rosenberg SA: Exploiting the curative potential of adoptive T-cell therapy for cancer. Immunol Rev 257: 56-71, 2014.

159. Jensen MC and Riddell SR: Designing chimeric antigen receptors to effectively and safely target tumors. Curr Opin Immunol 33: $9-15,2015$.

160.Eyquem J, Mansilla-Soto J, Giavridis T, van der Stegen SJ, Hamieh M, Cunanan KM, Odak A, Gönen M and Sadelain M: Targeting a CAR to the TRAC locus with CRISPR/Cas9 enhances tumour rejection. Nature 543: 113-117, 2017.

161. Cyranoski D: Chinese scientists to pioneer first human CRISPR trial. Nature 535: 476-477, 2016.

162. Topalian SL, Drake CG and Pardoll DM: Immune checkpoint blockade: A common denominator approach to cancer therapy. Cancer Cell 27: 450-461, 2015.

163. Yang Y, Kelly P, Shaffer AL III, Schmitz R, Yoo HM, Liu X, Huang DW, Webster D, Young RM, Nakagawa M, et al: Targeting non-proteolytic protein ubiquitination for the treatment of diffuse large B cell lymphoma. Cancer Cell 29: 494-507, 2016

164. DeWitt MA, Magis W, Bray NL, Wang T, Berman JR, Urbinati F, Heo SJ, Mitros T, Muñoz DP, Boffelli D, et al: Selection-free genome editing of the sickle mutation in human adult hematopoietic stem/progenitor cells. Sci Transl Med 8: 360ra134, 2016.

165.Zhen S, Hua L, Liu YH, Gao LC, Fu J, Wan DY, Dong LH, Song HF and Gao X: Harnessing the clustered regularly interspaced short palindromic repeat (CRISPR)/CRISPR-associated Cas9 system to disrupt the hepatitis B virus. Gene Ther 22: 404-412, 2015.

166. Dong C, Qu L, Wang H, Wei L, Dong Y and Xiong S: Targeting hepatitis B virus cccDNA by CRISPR/Cas9 nuclease efficiently inhibits viral replication. Antiviral Res 118: 110-117, 2015.

167. Price AA, Sampson TR, Ratner HK, Grakoui A and Weiss DS: Cas9-mediated targeting of viral RNA in eukaryotic cells. Proc Natl Acad Sci USA 112: 6164-6169, 2015.

168. Wang J and Quake SR: RNA-guided endonuclease provides a therapeutic strategy to cure latent herpesviridae infection. Proc Natl Acad Sci USA 111: 13157-13162, 2014.

169.Zhen S, Hua L, Takahashi Y, Narita S, Liu YH and Li Y: In vitro and in vivo growth suppression of human papillomavirus 16-positive cervical cancer cells by CRISPR/Cas9. Biochem Biophys Res Commun 450: 1422-1426, 2014

170.Leen AM, Myers GD, Sili U, Huls MH, Weiss H, Leung KS, Carrum G, Krance RA, Chang CC, Molldrem JJ, et al: Monoculture-derived $\mathrm{T}$ lymphocytes specific for multiple viruses expand and produce clinically relevant effects in immunocompromised individuals. Nat Med 12: 1160-1166, 2006.

171. Saglio F, Hanley PJ and Bollard CM: The time is now: Moving toward virus-specific $\mathrm{T}$ cells after allogeneic hematopoietic stem cell transplantation as the standard of care. Cytotherapy 16: 149-159, 2014

172. Lieberman J, Skolnik PR, Parkerson GR III, Fabry JA, Landry B, Bethel J and Kagan J: Safety of autologous, ex vivo-expanded human immunodeficiency virus (HIV)-specific cytotoxic T-lymphocyte infusion in HIV-infected patients. Blood 90: 2196-2206, 1997. 
173. Brodie SJ, Lewinsohn DA, Patterson BK, Jiyamapa D, Krieger J, Corey L, Greenberg PD and Riddell SR: In vivo migration and function of transferred HIV-1-specific cytotoxic T cells. Nat Med 5: 34-41, 1999.

174. Tan R, Xu X, Ogg GS, Hansasuta P, Dong T, Rostron T, Luzzi G, Conlon CP, Screaton GR, McMichael AJ, et al: Rapid death of adoptively transferred $\mathrm{T}$ cells in acquired immunodeficiency syndrome. Blood 93: 1506-1510, 1999.

175.Lam S, Sung J, Cruz C, Castillo-Caro P, Ngo M, Garrido C, Kuruc J, Archin N, Rooney C, Margolis D, et al: Broadlyspecific cytotoxic $\mathrm{T}$ cells targeting multiple HIV antigens are expanded from $\mathrm{HIV}^{+}$patients: implications for immunotherapy. Mol Ther 23: 387-395, 2015

176. Patel S, Lam S, Cruz CR, Wright K, Cochran C, Ambinder RF and Bollard CM: Functionally active HIV-specific T cells that target Gag and Nef can be expanded from virus-naive donors and target a range of viral epitopes: Implications for a cure strategy after allogeneic hematopoietic stem cell transplantation. Bio Blood Marrow Transplant 22: 536-541, 2016.

177.Sung JA, Lam S, Garrido C, Archin N, Rooney CM, Bollard CM and Margolis DM: Expanded cytotoxic T-cell lymphocytes target the latent HIV reservoir. J Infect Dis 212 258-263, 2015.

178. Colovos C, Villena-Vargas J and Adusumilli PS: Safety and stability of retrovirally transduced chimeric antigen receptor T cells. Immunotherapy 4: 899-902, 2012.

179. Scholler J, Brady TL, Binder-Scholl G, Hwang WT, Plesa G, Hege KM, Vogel AN, Kalos M, Riley JL, Deeks SG, et al: Decade-long safety and function of retroviral-modified chimeric antigen receptor T cells. Sci Transl Med 4: 132ra53, 2012.

180.Joseph A, Zheng JH, Follenzi A, Dilorenzo T, Sango K, Hyman J, Chen K, Piechocka-Trocha A, Brander C, Hooijberg E, et al: Lentiviral vectors encoding human immunodeficiency virus type 1 (HIV-1)-specific T-cell receptor genes efficiently convert peripheral blood CD8 T lymphocytes into cytotoxic T lymphocytes with potent in vitro and in vivo HIV-1-specific inhibitory activity. J Virol 82: 3078-3089, 2008.

181. Mitsuyasu RT, Anton PA, Deeks SG, Scadden DT, Connick E, Downs MT, Bakker A, Roberts MR, June CH, Jalali S, et al: Prolonged survival and tissue trafficking following adoptive transfer of CD4zeta gene-modified autologous CD4(+) and CD8(+) T cells in human immunodeficiency virus-infected subjects. Blood 96: 785-793, 2000.

182. Deeks SG, Wagner B, Anton PA, Mitsuyasu RT, Scadden DT, Huang C, Macken C, Richman DD, Christopherson C, June CH, et al: A phase II randomized study of HIV-specific T-cell gene therapy in subjects with undetectable plasma viremia on combination antiretroviral therapy. Mol Ther 5: 788-797, 2002.

183. Koretzky GA: Multiple roles of CD4 and CD8 in T cell activation. J Immunol 185: 2643-2644, 2010

184. Hütter G and Ganepola S: Eradication of HIV by transplantation of CCR5-deficient hematopoietic stem cells. Sci World J 11: 1068-1076, 2011.

185. Bitinaite J, Wah DA, Aggarwal AK and Schildkraut I: FokI dimerization is required for DNA cleavage. Proc Natl Acad Sci USA 95: 10570-10575, 1998

186. Yuan J, Wang J, Crain K, Fearns C, Kim KA, Hua KL, Gregory PD, Holmes MC and Torbett BE: Zinc-finger nuclease editing of human cxcr 4 promotes HIV-1 CD4(+) T cell resistance and enrichment. Mol Ther 20: 849-859, 2002.

187. Tebas P, Stein D, Tang WW, Frank I, Wang SQ, Lee G, Spratt SK, Surosky RT, Giedlin MA, Nichol G, et al: Gene editing of CCR5 in autologous CD4 T cells of persons infected with HIV. N Engl J Med 370: 901-910, 2014.

188. Pattanayak V, Ramirez CL, Joung JK and Liu DR: Revealing off-target cleavage specificities of zinc-finger nucleases by in vitro selection. Nat Methods 8: 765-770, 2011.

189. Hou P, Chen S, Wang S, Yu X, Chen Y, Jiang M, Zhuang K, Ho W, Hou W, Huang J, et al: Genome editing of CXCR4 by CRISPR/cas9 confers cells resistant to HIV-1 infection. Sci Rep 5: 15577, 2015

190. Kaminski R, Chen Y, Fischer T, Tedaldi E, Napoli A, Zhang Y, Karn J, Hu W and Khalili K: Elimination of HIV-1 genomes from human T-lymphoid cells by CRISPR/Cas9 gene editing. Sci Rep 6: 22555, 2016

191. Berger C, Jensen MC, Lansdorp PM, Gough M, Elliott C and Riddell SR: Adoptive transfer of effector $\mathrm{CD}^{+} \mathrm{T}$ cells derived from central memory cells establishes persistent $\mathrm{T}$ cell memory in primates. J Clin Invest 118: 294-305, 2008.
192. Chapuis AG, Casper C, Kuntz S, Zhu J, Tjernlund A, Diem K, Turtle CJ, Cigal ML, Velez R, Riddell S, et al: HIV-specific $\mathrm{CD}^{+} \mathrm{T}$ cells from $\mathrm{HIV}^{+}$individuals receiving HAART can be expanded ex vivo to augment systemic and mucosal immunity in vivo. Blood 117: 5391-5402, 2011.

193. Hashimoto $M$ and Takemoto T: Electroporation enables the efficient mRNA delivery into the mouse zygotes and facilitates CRISPR/Cas9-based genome editing. Sci Rep 5: 11315, 2015.

194. Chu VT, Weber T, Graf R, Sommermann T, Petsch K, Sack U, Volchkov P, Rajewsky K and Kühn R: Efficient generation of Rosa26 knock-in mice using CRISPR/Cas9 in C57BL/6 zygotes. BMC Biotechnol 16: 4, 2016.

195. Cottle RN, Lee CM, Archer D and Bao G: Controlled delivery of $\beta$-globin-targeting TALENs and CRISPR/Cas9 into mammalian cells for genome editing using microinjection. Sci Rep 5: 16031, 2015.

196. Oude Blenke E, Evers MJ, Mastrobattista E and van der Oost J: CRISPR-Cas9 gene editing: Delivery aspects and therapeutic potential. J Control Release 244: 139-148, 2016.

197. Han X, Liu Z, Jo MC, Zhang K, Li Y, Zeng Z, Li N, Zu Y and Qin L: CRISPR-Cas9 delivery to hard-to-transfect cells via membrane deformation. Sci Adv 1: e1500454, 2015.

198. D'Astolfo DS, Pagliero RJ, Pras A, Karthaus WR, Clevers H, Prasad V, Lebbink RJ, Rehmann H and Geijsen N: Efficient intracellular delivery of native proteins. Cell 161: 674-690, 2015.

199. Ha JS, Lee JS, Jeong J, Kim H, Byun J, Kim SA, Lee HJ, Chung HS, Lee JB and Ahn DR: Poly-sgRNA/siRNA ribonucleoprotein nanoparticles for targeted gene disruption. J Control Release 250: 27-35, 2017.

200. Sun W, Ji W, Hall JM, Hu Q, Wang C, Beisel CL and Gu Z: Self-assembled DNA nanoclews for the efficient delivery of CRISPR-Cas9 for genome editing. Angew Chem Int Ed Engl 54: 12029-12033, 2015.

201. Ramakrishna S, Kwaku Dad AB, Beloor J, Gopalappa R, Lee SK and Kim H: Gene disruption by cell-penetrating peptide-mediated delivery of Cas9 protein and guide RNA. Genome Res 24: 1020-1027, 2014.

202. Chew WL, Tabebordbar M, Cheng JK, Mali P, Wu EY, $\mathrm{Ng} \mathrm{AH}$, Zhu K, Wagers AJ and Church GM: A multifunctional AAV-CRISPR-Cas9 and its host response. Nat Methods 13: 868-874, 2016.

203. Long C, Amoasii L, Mireault AA, McAnally JR, Li H, Sanchez-Ortiz E, Bhattacharyya S, Shelton JM, Bassel-Duby R and Olson EN: Postnatal genome editing partially restores dystrophin expression in a mouse model of muscular dystrophy. Science 351: 400-403, 2016

204. Nelson CE, Hakim CH, Ousterout DG, Thakore PI, Moreb EA, Castellanos Rivera RM, Madhavan S, Pan X, Ran FA, Yan WX, et al: In vivo genome editing improves muscle function in a mouse model of Duchenne muscular dystrophy. Science 351: 403-407, 2016

205. Gomez EJ, Gerhardt K, Judd J, Tabor JJ and Suh J: Light-Activated Nuclear translocation of adeno-associated virus nanoparticles using phytochrome $\mathrm{B}$ for enhanced, tunable, and spatially programmable gene delivery. ACS Nano 10: 225-237, 2016.

206. Ran FA, Cong L, Yan WX, Scott DA, Gootenberg JS, Kriz AJ, Zetsche B, Shalem O, Wu X, Makarova KS, et al: In vivo genome editing using Staphylococcus aureus Cas9. Nature 520: 186-191, 2015.

207.Zuris JA, Thompson DB, Shu Y, Guilinger JP, Bessen JL, Hu JH, Maeder ML, Joung JK, Chen ZY and Liu DR: Cationic lipid-mediated delivery of proteins enables efficient proteinbased genome editing in vitro and in vivo. Nat Biotechnol 33: 73-80, 2015.

208. Wang M, Zuris JA, Meng F, Rees H, Sun S, Deng P, Han Y, Gao X, Pouli D, Wu Q, et al: Efficient delivery of genomeediting proteins using bioreducible lipid nanoparticles. Proc Natl Acad Sci USA 113: 2868-2873, 2016.

209. Gabriel R, Lombardo A, Arens A, Miller JC, Genovese P, Kaeppel C, Nowrouzi A, Bartholomae CC, Wang J, Friedman G, et al: An unbiased genome-wide analysis of zinc-finger nuclease specificity. Nat Biotechnol 29: 816-823, 2011.

210. Chiarle R, Zhang Y, Frock RL, Lewis SM, Molinie B, Ho YJ, Myers DR, Choi VW, Compagno M, Malkin DJ, et al: Genome-wide translocation sequencing reveals mechanisms of chromosome breaks and rearrangements in B cells. Cell 147: 107-119, 2011. 
211. Hsu PD, Scott DA, Weinstein JA, Ran FA, Konermann S, Agarwala V, Li Y, Fine EJ, Wu X, Shalem O, et al: DNA targeting specificity of RNA-guided Cas9 nucleases. Nat Biotechnol 31: 827-832, 2013.

212.Heigwer F, Kerr G and Boutros M: E-CRISP: Fast CRISPR target site identification. Nat Methods 11: 122-123, 2014.

213. Crosetto N, Mitra A, Silva MJ, Bienko M, Dojer N, Wang Q, Karaca E, Chiarle R, Skrzypczak M, Ginalski K, et al: Nucleotide-resolution DNA double-strand break mapping by next-generation sequencing. Nat Methods 10: 361-365, 2013 .

214.Kim D, Bae S, Park J, Kim E, Kim S, Yu HR, Hwang J, Kim JI and Kim JS: Digenome-seq: Genome-wide profiling of CRISPR-Cas9 off-target effects in human cells. Nat Methods 12: 237-243, 2015.

215. Tsai SQ,Zheng Z, Nguyen NT, Liebers M, Topkar VV, Thapar V, Wyvekens N, Khayter C, Iafrate AJ, Le LP, et al: GUIDE-seq enables genome-wide profiling of off-target cleavage by CRISPR-Cas nucleases. Nat Biotechnol 33: 187-197, 2015.

216. Fu Y, Sander JD, Reyon D, Cascio VM and Joung JK: Improving CRISPR-Cas nuclease specificity using truncated guide RNAs. Nat Biotechnol 32: 279-284, 2014.

217.Kim D, Kim S, Kim S, Park J and Kim JS: Genome-wide target specificities of CRISPR-Cas9 nucleases revealed by multiplex Digenome-seq. Genome Res 26: 406-415, 2016.

218. Frock RL, Hu J, Meyers RM, Ho YJ, Kii E and Alt FW: Genome-wide detection of DNA double-stranded breaks induced by engineered nucleases. Nat Biotechnol 33: 179-186, 2015.

219. Jinek M, Jiang F, Taylor DW, Sternberg SH, Kaya E, Ma E, Anders C, Hauer M, Zhou K, Lin S, et al: Structures of Cas9 endonucleases reveal RNA-mediated conformational activation. Science 343: 1247997, 2014.

220. Ran FA, Hsu PD, Lin C-Y, Gootenberg JS, Konermann S, Trevino AE, Scott DA, Inoue A, Matoba S, Zhang Y, et al: Double nicking by RNA-guided CRISPR Cas9 for enhanced genome editing specificity. Cell 154: 1380-1389, 2013.

221. McCaffrey J, Sibert J, Zhang B, Zhang Y, Hu W, Riethman H and Xiao M: CRISPR-CAS9 D10A nickase target-specific fluorescent labeling of double strand DNA for whole genome mapping and structural variation analysis. Nucleic Acids Res 44: e11 2016.

222. Tsai SQ, Wyvekens N, Khayter C, Foden JA, Thapar V, Reyon D, Goodwin MJ, Aryee MJ and Joung JK: Dimeric CRISPR RNA-guided FokI nucleases for highly specific genome editing. Nat Biotechnol 32: 569-576, 2014

223. Wyvekens N, Topkar VV, Khayter C, Joung JK and Tsai SQ: Dimeric CRISPR RNA-guided FokI-dCas9 nucleases directed by truncated gRNAs for highly specific genome editing. Hum Gene Ther 26: 425-431, 2015.

224. Kleinstiver BP, Pattanayak V, Prew MS, Tsai SQ, Nguyen NT, Zheng $\mathrm{Z}$ and Joung JK: High-fidelity CRISPR-Cas9 nucleases with no detectable genome-wide off-target effects. Nature 529: 490-495, 2016.

225. Hou Z, Zhang Y, Propson NE, Howden SE, Chu LF, Sontheimer EJ and Thomson JA: Efficient genome engineering in human pluripotent stem cells using Cas9 from Neisseria meningitidis. Proc Natl Acad Sci USA 110: 15644-15649, 2013.
226. Walsh RM and Hochedlinger K: A variant CRISPR-Cas9 system adds versatility to genome engineering. Proc Natl Acad Sci USA 110: 15514-15515, 2013.

227. Raza U, Saatci Ö, Uhlmann S, Ansari SA, Eyüpoğlu E, Yurdusev E, Mutlu M, Ersan PG, Altundağ MK, Zhang JD, et al: The miR-644a/CTBP1/p53 axis suppresses drug resistance by simultaneous inhibition of cell survival and epithelial-mesenchymal transition in breast cancer. Oncotarget 7: 49859-49877, 2016.

228. Singh R, Gupta SC, Peng WX, Zhou N, Pochampally R, Atfi A, Watabe K, Lu Z and Mo YY: Regulation of alternative splicing of Bcl-x by BC200 contributes to breast cancer pathogenesis. Cell Death Dis 7: e2262,2016.

229. Engel BJ, Bowser JL, Broaddus RR and Carson DD: MUC1 stimulates EGFR expression and function in endometrial cancer. Oncotarget 7: 32796-32809, 2016.

230. Zhang X, Choi PS, Francis JM, Imielinski M, Watanabe H, Cherniack AD and Meyerson M: Identification of focally amplified lineage-specific super-enhancers in human epithelial cancers. Nat Genet 48: 176-182, 2016.

231. Kavlashvili T, Jia Y, Dai D, Meng X, Thiel KW, Leslie KK and Yang S: Inverse relationship between progesterone receptor and Myc in endometrial cancer. PLoS One 11: e0148912, 2016.

232. Kawamura N, Nimura K, Nagano H, Yamaguchi S, Nonomura N and Kaneda Y: CRISPR/Cas9-mediated gene knockout of NANOG and NANOGP8 decreases the malignant potential of prostate cancer cells. Oncotarget 6: 22361-22374, 2015.

233. Mazur PK, Herner A, Mello SS, Wirth M, Hausmann S, SánchezRivera FJ, Lofgren SM, Kuschma T, Hahn SA, Vangala D, et al Combined inhibition of BET family proteins and histone deacetylases as a potential epigenetics-based therapy for pancreatic ductal adenocarcinoma. Nat Med 21: 1163-1171, 2015.

234.Zhang Z, Christin JR, Wang C, Ge K, Oktay MH and Guo W: Mammary-stem-cell-based somatic mouse models reveal breast cancer drivers causing cell fate dysregulation. Cell Rep 16: 3146-3156, 2016.

235. Walton J, Blagih J, Ennis D, Leung E, Dowson S, Farquharson M, Tookman LA, Orange C, Athineos D, Mason S, et al: CRISPR/ Cas9-mediated Trp53 and Brca2 knockout to generate improved murine models of ovarian high-grade serous carcinoma. Cancer Res 76: 6118-6129, 2016

236.Liang P, Xu Y, Zhang X, Ding C, Huang R, Zhang Z, Lv J, Xie X, Chen Y, Li Y, et al: CRISPR/Cas9-mediated gene editing in human tripronuclear zygotes. Protein Cell 6: 363-372, 2015.

This work is licensed under a Creative Commons Attribution-NonCommercial-NoDerivatives 4.0 International (CC BY-NC-ND 4.0) License. 